\title{
Front Matter: Volume 6937
}

, "Front Matter: Volume 6937," Proc. SPIE 6937, Photonics Applications in Astronomy, Communications, Industry, and High-Energy Physics Experiments 2007, 693749 (28 December 2007); doi: 10.1117/12.786497

SPIE Event: Photonics Applications in Astronomy, Communications, Industry, and High-Energy Physics Experiments 2007, 2007, Wilga, Poland 


\title{
PROCEEDINGS OF SPIE
}

\section{Photonics Applications in Astronomy, Communications, Industry, and High-Energy Physics Experiments 2007}

\author{
Ryszard S. Romaniuk \\ Editor
}

\section{1-27 May 2007 \\ Wilga, Poland}

\section{Organized by}

PERG and ELHEP Laboratories, Institute of Electronic Systems, Warsaw University of Technology (Poland) Student Branch, SPIE Poland Chapter (Poland) - Student Branch, IEEE Poland Section (Poland)

\section{Sponsored by}

IEEE Poland Section - SPIE Poland Chapter - Faculty of Electronics and Information Technologies, Warsaw University of Technology (Poland) • Institute of Electronic Systems, Warsaw University of Technology (Poland) • Committee of Electronics and Telecommunications, Polish Academy of Sciences (Poland) - Polish Committee of Optoelectronics, Association of Polish Electrical Engineers (Poland) Industrial Institute of Telecommunications, Warsaw (Poland) • Sottan Institute for Nuclear Studies, Świerk (Poland)

In Cooperation with CERN, Geneva (Switzerland) • DESY, Hamburg (Germany) • TTC-TESLA Technology Collaboration CARE-Coordinated Accelerator Research in Europe • ELAN-European Linear Accelerator Network CEA, DAPNIA, SACLAY (France) • XFEL, Poland Consortium

Published by

SPIE

Volume 6937 
The papers included in this volume were part of the technical conference cited on the cover and title page. Papers were selected and subject to review by the editors and conference program committee. Some conference presentations may not be available for publication. The papers published in these proceedings reflect the work and thoughts of the authors and are published herein as submitted. The publisher is not responsible for the validity of the information or for any outcomes resulting from reliance thereon.

Please use the following format to cite material from this book:

Author(s), "Title of Paper," in Photonics Applications in Astronomy, Communications, Industry, and High-Energy Physics Experiments 2007, edited by Ryszard S. Romaniuk, Proceedings of SPIE Vol. 6937 (SPIE, Bellingham, WA, 2007) Article CID Number.

ISSN 0277-786X

ISBN 9780819471246

Published by

SPIE

P.O. Box 10, Bellingham, Washington 98227-0010 USA

Telephone +1 3606763290 (Pacific Time) · Fax +1 3606471445

SPIE.org

Copyright (c) 2007, Society of Photo-Optical Instrumentation Engineers

Copying of material in this book for internal or personal use, or for the internal or personal use of specific clients, beyond the fair use provisions granted by the U.S. Copyright Law is authorized by SPIE subject to payment of copying fees. The Transactional Reporting Service base fee for this volume is $\$ 18.00$ per article (or portion thereof), which should be paid directly to the Copyright Clearance Center (CCC), 222 Rosewood Drive, Danvers, MA 01923. Payment may also be made electronically through CCC Online at copyright.com. Other copying for republication, resale, advertising or promotion, or any form of systematic or multiple reproduction of any material in this book is prohibited except with permission in writing from the publisher. The CCC fee code is $0277-786 \mathrm{X} / 07 / \$ 18.00$.

Printed in the United States of America.

Publication of record for individual papers is online in the SPIE Digital Library.

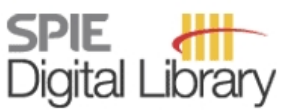

SPIEDigitalLibrary.org

Paper Numbering: Proceedings of SPIE follow an e-First publication model, with papers published first online and then in print and on CD-ROM. Papers are published as they are submitted and meet publication criteria. A unique, consistent, permanent citation identifier (CID) number is assigned to each article at the time of the first publication. Utilization of CIDs allows articles to be fully citable as soon they are published online, and connects the same identifier to all online, print, and electronic versions of the publication. SPIE uses a six-digit CID article numbering system in which:

- The first four digits correspond to the SPIE volume number.

- The last two digits indicate publication order within the volume using a Base 36 numbering system employing both numerals and letters. These two-number sets start with 00, 01, 02, 03, 04, 05, $06,07,08,09,0 \mathrm{~A}, 0 \mathrm{~B} \ldots \mathrm{OZ}$, followed by $10-1 \mathrm{Z}, 20-2 \mathrm{Z}$, etc.

The CID number appears on each page of the manuscript. The complete citation is used on the first page, and an abbreviated version on subsequent pages. Numbers in the index correspond to the last two digits of the six-digit CID number.

Proc. of SPIE Vol. 6937 693749-2 


\title{
Contents
}

\section{Part One}

\author{
xvii Patronage Committee \\ xix Symposium Committees \\ xxiii Conference Organizing Committee \\ xxv Conference Organizers \\ xxix Introduction \\ xliii Palindromes in mathematics (Plenary Paper) \\ W. Plandowski, Warsaw Univ. (Poland)
}

693701 In memory of Bohdan Paczyński (Invited Paper) [6937-01] M. Różyczka, Nicolaus Copernicus Astronomical Ctr. (Poland)

693702 Full Pi of the Sky system and simulation (Invited Paper) [6937-02]

J. Użycki, Warsaw Univ. of Technology (Poland); M. Ćwiok, Warsaw Univ. (Poland); L. Mankiewicz, Ctr. for Theoretical Physics (Poland); K. Nawrocki, M. Sokołowski, Sołtan Institute for Nuclear Studies (Poland); W. Tłaczała, Warsaw Univ. of Technology (Poland); G. Wrochna, Sottan Institute for Nuclear Studies (Poland)

693703 Period and variability type determination for the stars in the Pi of the Sky data [6937-03] A. Majczyna, Andrzej Sołtan Institute for Nuclear Study (Poland); M. Należyty, Warsaw Univ. Observatory (Poland); M. Biskup, Warsaw Univ. (Poland); M. Sokołowski, K. Nawrocki, G. Wrochna, Andrzej Sołtan Institute for Nuclear Study (Poland); L. Mankiewicz, Ctr. for Theoretical Physics (Poland)

693704 Providing on-line access to the Pi of the Sky data [6937-04] M. Biskup, Univ. of Warsaw (Poland); K. Malek, L. Mankiewicz, Ctr. for Theoretical Physics (Poland); L. W. Piotrowski, Univ. of Warszaw (Poland); M. Sokolowski, G. Wrochna, Sołtan Institute for Nuclear Studies (Poland); A. F. Zarnecki, Univ. of Warsaw (Poland)

693705 Web interface for star databases of the Pi of the Sky experiment [6937-05] M. Biskup, Warsaw Univ. (Poland); K. Małek, L. Mankiewicz, Ctr. for Theoretical Physics (Poland); M. Sokołowski, G. Wrochna, A. Sołtan Institute for Nuclear Studies (Poland)

693706 Algorithm for automatic estimation of quality of Pi of the Sky data [6937-06] J. Falzmann, L. Mankiewicz, Cardinal Stefan Wyszynski Univ. (Poland)

693707 Mechanical structure of the Pi of the Sky robotic telescope [6937-07] R. Pietrzak, P. Wawer, R. Wawrzaszek, J. Grygorczuk, J. Juchniewicz, Space Research Ctr. (Poland); L. Mankiewicz, Ctr. for Theoretical Physics (Poland); G. Wrochna, Sołtan Institute for Nuclear Studies (Poland) 
693708 Hardware emulator of the high-resolution CCD sensor for the Pi of the Sky experiment [6937-08]

G. Kasprowicz, Warsaw Univ. of Technology (Poland); L. Mankiewicz, Ctr. for Theoretical Physics (Poland); K. T. Pozniak, R. S. Romaniuk, S. Stankiewicz, Warsaw Univ. of Technology (Poland); G. Wrochna, Sottan Institute for Nuclear Studies (Poland)

693709 Nios II implementation in CCD camera for Pi of the Sky experiment [6937-09] M. Kwiatkowski, Sottan Institute for Nuclear Studies (Poland) and Warsaw Univ. of Technology (Poland); G. Kasprowicz, Warsaw Univ. of Technology (Poland); D. Rybka, Sołtan Institute for Nuclear Studies (Poland) and Warsaw Univ. of Technology (Poland); R. S. Romaniuk, K. T. Pozniak, Warsaw Univ. of Technology (Poland)

6937 OA Integrated extension board for on-board computer (OBDH) of SSETI ESEO satellite [6937-10] A. Cichocki, R. Graczyk, Warsaw Univ. of Technology (Poland)

6937 OB Performance comparison and selection criteria: an assessment for choosing the best flight detector for the SIR-2 NIR-spectrometer on Chandrayaan-1 [6937-11]

P. Sitek, Max-Planck Institute for Solar System Research (Germany) and Warsaw Univ. of Technology (Poland); E. Vilenius, U. Mall, Max Planck Institute for Solar System Research (Germany)

\section{SESSION 2 FLASH LASER AND EUROPEAN X-RAY LASER DEVELOPMENT}

6937 OC Distributed TRIDAQ systems for large HEP experiments: Part I. System architecture (Invited Paper) [6937-12]

K. T. Pozniak, Warsaw Univ. of Technology (Poland)

6937 OD Distributed TRIDAQ systems for large HEP experiments: Part II. Implementation for BAC (ZEUS at HERA) and RPC (CMS at LMC) detectors (Invited Paper) [6937-13]

K. T. Pozniak, Warsaw Univ. of Technology (Poland)

6937 OE Measurement and control of field in RF GUN at FLASH [6937-14]

A. Brandt, M. Hoffmann, Deutsches Elektronen-Synchrotron (Germany); W. Koprek, P. Pucyk, Deutsches Elektronen-Synchrotron (Germany) and Warsaw Univ. of Technology (Poland); S. Simrock, Deutsches Elektronen-Synchrotron (Germany); K. T. Pozniak, R. S. Romaniuk, Warsaw Univ. of Technology (Poland)

6937 OF Calibration procedure of extreme ultraviolet detectors [6937-15] J. Mikołajczyk, Z. Bielecki, Military Univ. of Technology (Poland); W. Kołosowski, E. Sędek, Telecommunications Research Institute (Poland)

6937 OG Multi-cavity complex controller with vector simulator for TESLA technology linear accelerator [6937-16]

T. Czarski, K. T. Pozniak, R. S. Romaniuk, J. Szewinski, Warsaw Univ. of Technology (Poland)

$6937 \mathrm{OH} \quad$ Versatile LLRF platform for FLASH laser [6937-17]

P. Strzałkowski, Warsaw Univ. of Technology (Poland); W. Koprek, Warsaw Univ. of Technology (Poland) and DESY (Germany); K. T. Poźniak, R. S. Romaniuk, Warsaw Univ. of Technology (Poland) 
6937 OI FPGA based PCI mezzanine card with digital interfaces [6937-18]

K. Lewandowski, R. Graczyk, K. T. Pozniak, R. S. Romaniuk, Warsaw Univ. of Technology (Poland)

6937 0J Data acquisition module implemented on PCI mezzanine card [6937-19]

L. Dymanowski, R. Graczyk, K. T. Pozniak, R. S. Romaniuk, Warsaw Univ. of Technology (Poland)

6937 OK Vector modulator board for X-FEL LLRF system [6937-20]

M. Smelkowski, P. Strzalkowski, K. T. Pozniak, Warsaw Univ. of Technology (Poland);

M. Hoffmann, German Electron Synchrotron DESY (Germany)

6937 OL FPGA systems development based on universal controller module [6937-21]

R. Graczyk, K. T. Poźniak, R. S. Romaniuk, Warsaw Univ. of Technology (Poland)

6937 OM DSP algorithms in FPGA: proposition of a new architecture [6937-22]

P. Kolasinski, W. Zabolotny, Warsaw Univ. of Technology (Poland)

6937 ON MatLab script to C code converter for embedded processors of FLASH LLRF control system [6937-23]

K. Bujnowski, A. Siemionczyk, Warsaw Univ. of Technology (Poland); P. Pucyk, Warsaw Univ. of Technology (Poland) and DESY (Germany); J. Szewiński, K. T. Poźniak, R. S. Romaniuk, Warsaw Univ. of Technology (Poland)

693700 Decomposition of MATLAB script for FPGA implementation of real time simulation algorithms for LLRF system in European XFEL [6937-24]

K. Bujnowski, Warsaw Univ. of Technology (Poland); P. Pucyk, Warsaw Univ. of Technology (Poland) and Deutsches Elektronen-Synchrotron (Germany); K. T. Pozniak, R. S. Romaniuk, Warsaw Univ. of Technology (Poland)

6937 OP FPGA control utility in JAVA [6937-25]

P. Drabik, K. T. Pozniak, Warsaw Univ. of Technology (Poland)

\section{SESSION 3 SUPERCONDUCTIVE ACCELERATOR TECHNOLOGY FOR FREE ELECTRON LASER AND HIGH} ENERGY PHOTON PHYSICS

$69370 Q$ Recent achievements in ultra-high vacuum arc deposition of superconducting Nb layers [6937-26]

L. Catani, A. Cianchi, INFN Roma Tor Vergata (Italy); D. Di Giovenale, R. Polini, S. Tazzari, Univ. di Roma Tor Vergata (Italy); J. Lorkiewicz, M. J. Sadowski, P. Strzyżewski, Andrzej Sottan Institute for Nuclear Studies (Poland); B. Ruggiero, R. Russo, Istituto di Cibernetica del CNR and INFN-Na (Italy)

6937 OR Copper TESLA structure: measurements and control [6937-27]

J. Główka, M. Maciaś, Warsaw Univ. of Technology (Poland)

6937 OS Pd nanocrystalline films for electron sources [6937-28]

E. Czerwosz, Świętokrzyska Academy (Poland) and Industrial Institute of Electronics (Poland); R. Diduszko, Industrial Institute of Electronics (Poland); P. Dłużewski, Institute of Physics (Poland); J. Kęczkowska, Kielce Univ. of Technology (Poland); M. Kozłowski, Industrial Institute of Electronics (Poland) and Institute of Physics (Poland); M. Suchańska, Kielce Univ. of Technology (Poland) 
6937 OT Copper electropolishing versus electrodes modificating electric field in the electrocrystallization process [6937-29]

A. Bialostocka, L. Zaniewski, Białystok Technical Univ. (Poland)

6937 OU FPGA based triggers in the Pierre Auger Observatory [6937-30]

Z. Szadkowski, Univ. of Łódź (Poland)

6937 OV Data acquisition card for CERN proton synchrotron beam current transformers [6937-31]

G. Kasprowicz, Warsaw Univ. of Technology (Poland) and European Organization for Nuclear Research (Switzerland)

6937 OW Direct digital modulation system for LLRF [6937-32]

S. Tarnowski, A. Piotrowski, A. Napieralski, Technical Univ. of Łódź (Poland)

6937 OX AVR microcontroller simulator for a software implemented hardware fault tolerance algorithms research [6937-33]

A. Piotrowski, S. Tarnowski, A. Napieralski, Technical Univ. of Łódź (Poland)

6937 OY Partial reconfiguration-oriented design of logic controllers [6937-34]

M. Doligalski, M. Węgrzyn, Univ. of Zielona Góra (Poland)

\section{SESSION 4 PHOTOACOUSTICS AND ULTRASHORT PULSE TECHNOLOGY}

$6937 \mathrm{OZ}$ Comparison of FFT and LMS applied to photoacoustic signal detection [6937-35]

T. Starecki, T. Owczarek, Warsaw Univ. of Technology (Poland)

693710 Comparison of photoacoustic Helmholtz resonator models [6937-36]

M. Suchenek, Warsaw Univ. of Technology (Poland)

693711 A pulser with inverted microstrip line for time-domain reflectometry [6937-37]

K. Opalska, S. Misiaszek, Warsaw Univ. of Technology (Poland)

693712 Low-cost trigger circuit for sampling oscilloscope [6937-38]

A. Burd, K. Opalska, Warsaw Univ. of Technology (Poland)

693713 Statistical method of evaluation of flip-flop dynamical parameters [6937-39]

P. Z. Wieczorek, L. J. Opalski, Warsaw Univ. of Technology (Poland)

693714 Design of two-channel oscilloscope and basic circuit simulations in LabView [6937-40]

P. Balzhiev, Technical Univ. of Sofia (Bulgaria); J. Makal, Białystok Technical Univ. (Poland)

\section{SESSION 5 OPTICAL FIBER TECHNOLOGY AND MEASUREMENTS}

$693715 \quad$ Nonlinear glasses and metaglasses for photonics, a review: Part I. Nonlinear electrical susceptibility and refractive index (Invited Paper) [6937-41]

R. S. Romaniuk, Warsaw Univ. of Technology (Poland)

$693716 \quad$ Nonlinear glasses and metaglasses for photonics, a review: Part II. Kerr nonlinearity and metaglasses of positive and negative refraction (Invited Paper) [6937-42]

R. S. Romaniuk, Warsaw Univ. of Technology (Poland) 
693717 Pulse generation, spectroscopy, and transitions dynamics of Er ${ }^{3+}$ ions in YAG host [6937-43] P. Konieczny, J. Świderski, A. Zając, Military Univ. of Technology (Poland)

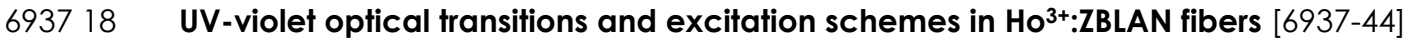

M. Klimczak, M. Cieślik, M. Kaczkan, P. Witoński, Institute of Microelectronics and

Optoelectronics (Poland); R. Piramidowicz, Institute of Microelectronics and

Optoelectronics (Poland) and Telekomunikacja Polska Research and Development Ctr. (Poland)

693719 Erbium doped glasses for optical fiber amplifiers [6937-45]

J. Wójcik, D. Dorosz, Białystok Univ. of Technology (Poland)

6937 1A Measurements of relaxation time of fiber amplifiers [6937-46]

A. Spławska, Poznan Univ. of Technology (Poland)

6937 1B Analysis of the work of non-uniform fiber Bragg grating as a transducer of impulsive strains [6937-47]

A. Sikora, Kielce Univ. of Technology (Poland)

6937 1C Fiber Bragg grating reconstruction by using the genetic algorithm [6937-48]

W. Wójcik, P. Kisała, S. Cięszczyk, Lublin Univ. of Technology (Poland)

6937 ID The manufacturing of polarization optical fibres [6937-49]

A. Zadykowicz, D. Dorosz, Białystok Univ. of Technology (Poland)

$69371 \mathrm{E}$ The properties of polarization fibers [6937-50]

A. Zadykowicz, D. Dorosz, Białystok Univ. of Technology (Poland)

$6937 \mathrm{IF}$ The manufacturing and properties of double-clad optical fibres [6937-51]

M. Kochanowicz, D. Dorosz, Białystok Univ. of Technology (Poland)

\section{SESSION 6 OPTICAL FIBER APPLICATIONS}

6937 1G A proposition of multi-parameter photonic method for nano-liter samples examination of liquids with short sections of optical capillaries [6937-52]

M. Borecki, Warsaw Univ. of Technology (Poland); M. L. Korwin-Pawlowski, Univ. du Québec en Outaouais (Canada); M. Bebłowska, P. Wrzosek, Warsaw Univ. of Technology (Poland)

$6937 \mathrm{1H} \quad$ Multimode fiber refractive index profile considerations for mode group diversity multiplexing [6937-53]

G. Stepniak, Warsaw Univ. of Technology (Poland)

693711 Incremental optical fibre transmission and reflection sensors [6937-54]

J. Kusznier, Białystok Univ. of Technology (Poland)

$69371 \mathrm{~J}$ The temperature sensor based on capillary waveguide [6937-55]

P. Miluski, D. Dorosz, Białystok Univ. of Technology (Poland)

$69371 \mathrm{~K}$ Optical transmission of the active power filter cooperating with battery energy storage control system [6937-56]

A. Kuźma, M. Zajkowski, Białystok Technical Univ. (Poland) 
6937 IL Using the CCD camera to record the radiation emitted by an LED matrix [6937-57]

J. Parzych, Poznan Univ. of Technology (Poland)

6937 1M Low electric power supply via optical fibre [6937-58]

W. Wójcik, A. Smolarz, T. Zyska, Z. Lach, Lublin Univ. of Technology (Poland)

6937 iN Guiding of Rb atoms by capillary optical fibres [6937-59]

A. Iwaniuk, J. Dorosz, Białystok Univ. of Technology (Poland)

693710 Measurement and analysis of polarization mode dispersion [6937-60]

S. A. Torbus, Technical Telematic School (Poland)

\section{SESSION 7 NANOMATERIALS AND MATERIAL RESEARCH FOR PHOTONICS AND ELECTRONICS}

6937 IP X-ray diffraction as a tool of ORMOSIL gels' structure's investigation [6937-61]

E. M. Chodkowska, J. Rayss, Maria Curie-Sklodowska Univ. (Poland)

6937 1Q Hybrid microstructures for capillary electrophoresis with micro-channel in photosensitive layer [6937-62]

I. Wyżkiewicz, Institute of Electronic Materials Technology (Poland); N. Górniak, Warsaw Univ. of Technology (Poland); M. Jakubowska, Institute of Electronic Materials Technology (Poland); Z. Brzózka, A. Dybko, Warsaw Univ. of Technology (Poland)

6937 IR High density packing and interconnections for hybrid microelectronics: new trends in materials development (Invited Paper) [6937-63]

M. Jakubowska, Technical Univ. of Warsaw (Poland) and Institute of Electronic Materials Technology (Poland)

6937 is Thick-film gold and platinum conducing paths for high temperature electronics [6937-64] M. Jakubowska, Institute of Electronic Materials Technology (Poland); J. Kalenik, Warsaw Univ. of Technology (Poland); K. Kiełbasiński, Institute of Electronic Materials Technology (Poland) and Warsaw Univ. of Technology (Poland); A. Młożniak, E. Zwierkowska, Institute of Electronic Materials Technology (Poland)

6937 1T Quality estimation of thick-film resistor terminations based on electrical parameters extraction [6937-65]

K. Kiełbasiński, Institute of Electronic Materials Technology (Poland) and Warsaw Univ. of Technology (Poland); M. Jakubowska, Institute of Electronic Materials Technology (Poland); J. Kalenik, Warsaw Univ. of Technology (Poland); A. Młożniak, Institute of Electronic Materials Technology (Poland)

6937 iU Efficient defect structure analysis in semi-insulating materials by support vector machine and relevance vector machine [6937-66]

S. Jankowski, J. Będkowski, P. Danilewicz, Z. Szymański, Warsaw Univ. of Technology (Poland)

6937 IV Application of local cluster neural network to detect structure analysis of semi-insulating GaAs [6937-67]

S. Jankowski, T. P. Pichlak, Warsaw Univ. of Technolgy (Poland) 
6937 IW Recognition of defect structure of Si(A4) by on-line support vector machine [6937-68]

T. Dziedzic, J. Będkowski, S. Jankowski, Warsaw Univ. of Technology (Poland)

6937 1X Selection of significant samples to reduce the complexity of least-squares support vector machine [6937-69]

G. Di Salvo, Univ. degli Studi di Catania (Italy); S. Jankowski, E. Piątkowska-Janko, Warsaw Univ. of Technology (Poland); P. Arena, Univ. degli Studi di Catania (Italy)

6937 IY Multiwalled carbon nanotubes deposition in thick film silver conductor [6937-70]

M. Słoma, Warsaw Univ. of Technology (Poland); M. Jakubowska, A. Młożniak, Institute of Electronic Materials Technology (Poland)

693712 The observed perturbations in $v^{\prime}=11$ of $A^{1} \Pi$ state of ${ }^{13} C^{16} \mathrm{O}$ molecule [6937-71]

J. Domin, P. Malita, D. Rylska, Rzeszów Univ. of Technology (Poland)

693720 Evaluation of elasticity modulus for textiles filament [6937-72]

T. Więcek, \&. Pękala, A. Podkościelny, A. Wasilewski, Rzeszów Univ. of Technology (Poland)

693721 Determination of Poisson's ration for auxetic materials [6937-73]

T. Więcek, A. Belczyk, M. Pucher, A. Wasilewski, Rzeszów Univ. of Technology (Poland)

\section{Part Two}

SESSION 8

TOWARD OPTICAL AND QUANTUM CRYPTOGRAPHY

693722 Introduction to optical quantum cryptography (Invited Paper) [6937-74]

T. Adamski, Warsaw Univ. of Technology (Poland)

693723 Searching for hard instances of CVP problem-cryptographic perspective [6937-75]

J. Pardyak, Warsaw Univ. of Technology (Poland)

693724 Analysis of simple current sources and sinks for differential current mode technology [6937-76]

K. Gołofit, Warsaw Univ. of Technology (Poland)

693725 Improving hard disk data security using a hardware encryptor [6937-77]

A. Walewski, Warsaw Univ. of Technology (Poland)

\section{SESSION 9 MEDICAL X-RAY ACCELERATORS AND BIOMEDICAL APPLICATIONS}

693726 Numerical solution of tissue laser welding problem [6937-78]

Ł. Urbański, D. Podniesiński, A. Zając, Military Univ. of Technology (Poland)

$693727 \quad$ Multileaf collimator for Coline medical accelerators [6937-79]

J. Harasimowicz, G. Plebański, K. Sajna, Sołtan Institute for Nuclear Studies (Poland)

693728 Control systems for Coline accelerators [6937-80]

A. Baczewski, A. Latała, K. Ceglińska, M. Andrasiak, Sołtan Institute for Nuclear Studies (Poland) 
693729 Parallel computation of the SAR distribution in a 3D human head model [6937-81]

W. Walendziuk, Białystok Technical Univ. (Poland)

6937 2A Wireless platform for smart sensor networks [6937-82]

M. Kowalska, J. Weremczuk, Warsaw Univ. of Technology (Poland)

6937 2B Graphical user interface for wireless sensor networks simulator [6937-83]

T. Paczesny, D. Paczesny, J. Weremczuk, Warsaw Univ. of Technology (Poland)

6937 2C Electronic control unit for two stream humidity generator [6937-84]

R. Iwaszko, J. Weremczuk, Warsaw Univ. of Technology (Poland)

$69372 \mathrm{D}$ Electronic rhinological thermometer for three-point air temperature measurement in nasal cavity [6937-85]

M. Śnieg, D. Paczesny, J. Weremczuk, Warsaw Univ. of Technology (Poland)

6937 2E Application of neural classifier to risk recognition of sustained ventricular tachycardia and flicker in patients after myocardial infarction based on high-resolution electrocardiography [6937-86]

J. Wydrzyński, S. Jankowski, E. Piątkowska-Janko, Warsaw Univ. of Technology (Poland)

SESSION 10 WARMER PROGRAM-SENSORY NETWORKS FOR WATER MANAGEMENT/PRESERVATION AND ENVIRONMENTAL PROTECTION

$69372 \mathrm{~F}$ Toward a web enabled multi-sensor monitoring system: the EU FP6 WARMER project (Invited Paper) [6937-87]

A. Filipkowski, L. J. Opalski, Warsaw Univ. of Technology (Poland)

$69372 \mathrm{G}$ System architecture and sensor probes for the WARMER project [6937-88]

H. Sz. Drabczyk, L. J. Opalski, Warsaw Univ. of Technology (Poland)

$69372 \mathrm{H} \quad$ OGC SWE in WARMER project [6937-89]

H. Sz. Drabczyk, Warsaw Univ. of Technology (Poland)

$693721 \quad$ Modeling of potentiometric sensors sensitive to ions of valency one and two for possible applications in WARMER project (Invited Paper) [6937-90]

J. Ogrodzki, Warsaw Univ. of Technology (Poland)

6937 2J Electrical properties of potentiometric sensors: an empirical study [6937-91]

P. Z. Wieczorek, L. J. Opalski, J. Ogrodzki, Warsaw Univ. of Technology (Poland)

\section{SESSION 11 IMAGE PROCESSING}

6937 2K Fuzzy description of image processing [6937-92]

B. S. Butkiewicz, Warsaw Univ. of Technology (Poland)

6937 2L Parametric approach to the retrieval of lossy compressed color images [6937-93]

M. Luszczkiewicz, B. Smolka, Silesian Univ. of Technology (Poland) 
$69372 \mathrm{M}$ Visual analysis of multidimensional data using fast MDS algorithm [6937-94]

P. Pawliczek, W. Dzwinel, AGH Univ. of Science and Technology (Poland)

$69372 \mathrm{~N}$ Application of algebraic graph descriptors for clustering of real-world structures [6937-95] W. Czech, AGH Univ. of Science and Technology (Poland)

693720 Text localization in natural scene images using multiple classifiers [6937-96]

A. Kozłowski, P. Strumiłło, Technical Univ. of Łódź (Poland)

$69372 \mathrm{P} \quad$ Statistical properties of human images obtained by generalized portrait method [6937-97] L. V. Kolchenko, R. B. Sinitsyn, National Aviation Univ. (Ukraine)

$69372 \mathrm{Q}$ A method for verification of dense disparity maps computed from the matching algorithm implemented in the stereovision system [6937-98]

D. Rzeszotarski, P. Skulimowski, P. Strumiłło, Technical Univ. of Łódź (Poland)

$69372 R \quad$ Digital image colorization based on distance transformation [6937-99]

P. Lagodzinski, B. Smolka, Silesian Univ. of Technology (Poland)

$69372 \mathrm{~S}$ Color calibration and detection for 3D object modelling with color structured light [6937-100]

A. Ołdak, W. Skarbek, Warsaw Univ. of Technology (Poland)

6937 2T Code domain steganography in video tracks [6937-101]

S. Rymaszewski, Warsaw Univ. of Technology (Poland)

$69372 \mathrm{U}$ Zonal compression of greyscale images using Walsh and PWL transforms [6937-102]

D. Wiraszka, R. Spadło, Kielce Univ. of Technology (Poland)

6937 2V Minutiae matching using local pattern features [6937-103]

M. Jędryka, Z. Wawrzyniak, Warsaw Univ. of Technology (Poland)

6937 2W Ka-band bistatic ground-based SAR using noise signals (Invited Paper) [6937-104] K. Lukin, A. Mogyla, P. Vyplavin, V. Palamarchuk, O. Zemlyaniy, V. Tarasenko, N. Zaets, V. Skretsanov, A. Shubniy, V. Glamazdin, M. Natarov, O. Nechayev, Usikov Institute for Radiophysics and Electronics (Ukraine)

$69372 X \quad$ Antenna array with synthetic aperture [6937-105]

K. Lukin, A. Mogyla, P. Vyplavin, Usikov Institute for Radiophysics and Electronics (Ukraine)

$69372 Y$ Implementation of phase gradient autofocus algorithm for spotlight SAR [6937-106]

M. Kuźniak, M. Malanowski, Warsaw Univ. of Technology (Poland)

$69372 Z$ Influence of integration time on tracking performance in PCL radar [6937-107]

M. Malanowski, Warsaw Univ. of Technology (Poland)

693730 Increasing the classification performance of a classifier via sub-space based classifications [6937-108]

K. Rosenbach, J. Schiller, Research Establishment for Applied Sciences (Germany) 
693731 Passive radar prototypes for multifrequency target detection [6937-109]

C. Bongioanni, F. Colone, S. Bernardini, L. Lelli, A. Stavolo, P. Lombardo, Univ. of Rome La Sapienza (Italy)

693732 Multilook colour mapping in SAR images [6937-110]

A. Gadoś, A. Gorzelańczyk, Telecommunications Research Institute (Poland); K. Kulpa, Warsaw Univ. of Technology (Poland); M. Mordzonek, P. Samczyński, M. Smolarczyk, Telecommunications Research Institute (Poland)

693733 Resampling methods for stretch processing in PCL radars [6937-111] J. Misiurewicz, Warsaw Univ. of Technology (Poland)

693734 Noise radar target defection in the presence of alpha-stable noise [6937-112] Z. Gajo, M. Malanowski, Warsaw Univ. of Technology (Poland)

693735 Simple SAR demonstrator [6937-113]

K. Kulpa, J. Misiurewicz, Warsaw Univ. of Technology (Poland); P. Baranowski, Univ. of Warsaw (Poland); G. Wojdołowicz, ORPAL (Poland)

\section{SESSION 13 SIGNAL PROCESSING}

693736 Fuzzy analog and discrete time invariant systems (Invited Paper) [6937-114]

B. S. Butkiewicz, Warsaw Univ. of Technology (Poland)

693737 Synthesizing a 3D auditory scene for use in an electronic travel aid for the blind [6937-115] M. Bujacz, P. Strumiłło, Technical Univ. of Łódź (Poland)

693738 Storing digital data using zero-compression method [6937-116]

A.-R. Al-Qawasmi, Philadelphia Univ. (Jordan); A. Al-Lawama, Mutah Univ. (Jordan)

693739 Kernel estimate of the spoken language sound multivariate probability density function [6937-117]

Z. M. Bokal, R. B. Sinitsyn, National Aviation Univ. (Ukraine)

6937 3A Precision matrix as a construction tool of line estimators [6937-1 18]

J. Karwatka, P.I.T. Telecommunications Research Institute (Poland)

6937 3B Comparison of eyeblink monitoring and EEG signal analysis for mental fatigue assessment [6937-119]

A. Królak, P. Strumiłło, Technical Univ. of Łódź (Poland)

6937 3C Head related transfer functions measurement and processing for the purpose of creating a spatial sound environment [6937-120]

M. Pec, M. Bujacz, P. Strumiłło, Technical Univ. of Łódź (Poland)

6937 3D Support vector machines: heuristic of alternatives [6937-121]

M. Orchel, AGH Univ. of Science and Technology (Poland)

6937 3E Method for edge detection in images using fuzzy relation [6937-122]

G. Nieradka, Warsaw Univ. of Technology (Poland) 
6937 3F Voice activity detection for speaker verification systems [6937-123]

F. Borowski, Warsaw Univ. of Technology (Poland)

6937 3G Reflections from raindrops in case of turbulence: phenomenological analysis and signal processing (Invited Paper) [6937-124]

Y. S. H. Khraisat, Al-Balqa Applied Univ. (Jordan); F. J. Yanovsky, National Aviation Univ. (Ukraine)

$69373 \mathrm{H} \quad$ Situation analysis for automotive pre-crash systems (Invited Paper) [6937-125]

M. A. Böhning, H. Ritter, H. Rohling, Hamburg Univ. of Technology (Germany)

6937 31 Through the wall seeing in the ELF band [6937-126]

J. Cechak, Univ. of Defence (Czech Republic)

6937 3J Two Dirac-Deltas detector analysis for target detection in non-Gaussian sea clutter [6937-127]

T. Górski, Military Univ. of Technology (Poland) and GET, École Nationale Supérieure des Télécommunications de Bretagne (France); A. Kawalec, W. Czarnecki, Military Univ. of Technology (Poland); J.-M. Le Caillec, L. Lecornu, GET, École Nationale Supérieure des Télécommunications de Bretagne (France)

6937 3K Influence of a non-Gaussian state model on the position estimation in the nonlinear filtration [6937-128]

S. Konatowski, Military Univ. of Technology (Poland); B. Pudlak, Consultant (Poland)

6937 L LFM radar signal detection in the joint time-frequency domain [6937-129]

Y. Grishin, W. Niczyporuk, Białystok Technical Univ. (Poland)

$69373 \mathrm{M}$ Correction of radar signal on elevation angle when reflecting from turbulent zone [6937-130]

Yu. Averyanova, A. Averyanov, F. Yanovsky, National Aviation Univ. (Ukraine)

$69373 \mathrm{~N}$ Computer-aided methods of the LPI radar signal detection and classification [6937-131]

Y. Grishin, D. Janczak, Białystok Technical Univ. (Poland)

693730 Time-frequency Zadeh filtering in estimation of radar signals embedded in non-Gaussian disturbances [6937-132]

E. Swiercz, Białystok Technical Univ. (Poland)

6937 3P The digital electronic intelligence (ELINT) receiver [6937-133]

P. Hubáček, J. Veselý, Univ. of Defence (Czech Republic)

$69373 Q \quad$ An extreme value theory approach to correlated radar clutter [6937-134] M. Piotrkowski, Warsaw Univ. of Technology (Poland) 
$69373 R \quad$ Scanning nanojet lithograph and microscope [6937-135]

I. A. Timoshchenko, Belarusian State Univ. (Belarus)

6937 3S Computer aided designing of microwave frequency discriminator [6937-136]

P. Kaczmarek, Military Univ. of Technology (Poland)

6937 3T Just noticeable difference level estimation in real-time digital signal processing [6937-137] Z. Piotrowski, W. Rudkowski, Military Univ. of Technology (Poland)

6937 3U Phase drift effect minimization in HF/VHF radio links using phase drift scanner method [6937-138]

Z. Piotrowski, P. Gajewski, Military Univ. of Technology (Poland)

6937 3V Smart dust technology for detection and identification of persons [6937-139]

J. Cechak, Univ. of Defence (Czech Republic)

6937 3W Code-division multiple-access protocol for active RFID systems [6937-140]

G. Mazurek, J. Szabatin, Warsaw Univ. of Technology (Poland)

$69373 X \quad$ Flexible hardware plafform for software radio experiments [6937-141]

G. Mazurek, M. Malanowski, K. Kulpa, Warsaw Univ. of Technology (Poland)

\section{SESSION 16 OPTICAL MEASUREMENTS}

6937 3Y Optical measurement technology and systems in the Institute of Applied Optics [6937-142]

J. Galas, D. Litwin, Institute of Applied Optics (Poland)

$69373 Z$ Present design and lens axicons and their history [6937-143]

K. Kołacz, Institute of Applied Optics (Poland); A. Burvall, A. Goncharov, National Univ. of Ireland, Galway (Ireland); Z. Jaroszewicz, Institute of Applied Optics (Poland) and National Institute of Telecommunications (Poland); C. Dainty, National Univ. of Ireland, Galway (Ireland); A. T. Friberg, Royal Institute of Technology (Sweden)

693740 Silicon wafers for scanning helium microscopy [6937-144]

D. Litwin, J. Galas, S. Sitarek, Institute of Applied Optics (Poland)

693741 A method of measurement of gradient-index elements [6937-145]

M. Wychowaniec, Instytut Optyki Stosowanej (Poland)

693742 Optical properties of the grating with 1300 lines/mm at PGS-2 spectrograph [6937-146]

J. Domin, J. Fal, A. Kądziołka, Ł. Tylski, Rzeszów Univ. of Technology (Poland)

$693743 \quad$ Algorithms for data processing in FSCW systems [6937-147]

K. Korszeń, National Institute of Telecommunications (Poland); J. Dawidczyk, Warsaw Univ. of Technology (Poland) 
693744 The algorithm of optimal linearization of non-linear state equation [6937-148]

J. Forenc, Białystok Technical Univ. (Poland)

693745 The selected aspects of the global linearization of non-linear state equation [6937-149] P. Myszkowski, Białystok Technical Univ. (Poland)

693746 The use of parallel computations in a 2D numerical simulation of non-stationary thermal field in a cylindrical wire [6937-150]

J. Gołębiowski, R. P. Bycul, Białystok Technical Univ. (Poland)

693747 A bridge-circuit for experimental simulation of quasi-static bending tests [6937-151]

A. Idzkowski, W. Walendziuk, Białystok Technical Univ. (Poland)

693748 Simulation of the voltage transformer metrological characteristics [6937-152]

M. Kaczmarek, R. Chmielecki, Technical Univ. of Łódź (Poland)

Author Index 
Proc. of SPIE Vol. 6937 693749-16

Downloaded From: https://www.spiedigitallibrary.org/conference-proceedings-of-spie on 25 Apr 2023 Terms of Use: https://www.spiedigitallibrary.org/terms-of-use 


\section{Wilga Symposia Permanent Patronage Committee}

Prof. Jan Dorosz, WILGA Symposium Program Committee Chair, Faculty of Electrical Engineering, Bialystok Univ. of Technology (Poland) (doroszjan@pb.bialystok.pl)

Prof. Henryk Fiedorowicz, Director of Institute of Optoelectronics, Military Academy of Technology, Warsaw (Poland) (hfiedorowicz@wat.edu.pl)

Dr. Jacek Galas, vice-Director of Institute of Applied Optics, Warsaw (Poland) (galas@inos.pl)

Prof. Bogdan Galwas, Dean of the Faculty of Electronics and Information Technologies, Institute of Telecommunication, Warsaw University of Technology (Poland) (b.galwas@elka.pw.edu.pl)

Prof. Marian P. Kaźmierkowski, Past Chair of IEEE Poland Section, Director of Institute of Control and Industrial Electronics, Faculty of Electrical Engineering, Warsaw University of Technology (Poland)

(mpk@isep.pw.edu.pl)

Prof. Jerzy Klamka, Association of Polish Electrical Engineers, Editor-in-Chief of Elektronika Monthly (Poland) (elektronika@red.pl.pl)

Dr. Dariusz Litwin, vice-Director of Institute of Applied Optics, Warsaw (Poland) (dlitwin@inos.pl)

Prof. Andrzej Pacut, Chair of IEEE Poland Section, Institute of Control and Computation Engineering, Faculty of Electronics and Information Technologies, Warsaw University of Technology (Poland) (a.pacut@ia.pw.edu.pl)

Prof. Ryszard S. Romaniuk, WILGA Symposium Chair, Chair of PERG/ELHEP Laboratory, Institute of Electronic Systems, FE\&IT, Warsaw University of Technology, (Poland) (r.romaniuk@spie.pl)

Prof. Jerzy Szabatin, Director of Institute of Electronic Systems, Faculty of Electronics and Information Technologies, Warsaw University of Technology (Poland) (j.szabatin@ise.pw.edu.pl)

Prof. Tomasz R. Woliński, Chair of SPIE Poland Chapter, Director of Optics Division, Faculty of Physics, Warsaw University of Technology, (Poland) (wolinski@if.pw.edu.pl) 
Prof. Wiesław L. Woliński, Corresponding Member of Polish Academy of Sciences, Chair of Electronics and Telecommunications Committee of Polish Academy of Sciences, Chair of Polish Optoelectronics Committee,

Association of Polish Electrical Engineers, Institute of Micro and Optoelectronics, FE\&IT, Warsaw University of Technology (Poland) (w.wolinski@elka.pw.edu.pl)

Prof. Grzegorz Wrochna, Director of Sottan Institute for Nuclear Studies, Warsaw (Poland) and CERN, Geneva (Switzerland) (wrochna@fuw.edu.pl)

Prof. Andrzej Zajac, Institute of Optoelectronics, Military Academy of Technology, Warsaw (Poland) (A.zajac@pb.bialystok.pl) 


\section{Wilga 2007 Symposium Committees}

General Chair

Ryszard S. Romaniuk, Warsaw University of Technology (Poland)

Symposium Chair

Jan Dorosz, Białystok University of Technology (Poland)

Photonics and Electronics for Astronomy and High Energy Physics Experiments Conference Chairs

Ryszard S. Romaniuk, PERG/ELHEP Laboratory, Institute of Electronic Systems, FE\&IT, Warsaw University of Technology, (Poland)

Grzegorz Wrochna, Sottan Institute for Nuclear Studies, Warsaw (Poland) and CERN, Geneva (Switzerland)

\section{Photonics and Web Engineering}

Conference Chair

Jan Dorosz, Białystok University of Technology (Poland)

\section{Photonics Technologies}

Conference Chairs

Ryszard Kisiel, Warsaw University of Technology (Poland)

Michał Borecki, Warsaw University of Technology (Poland)

Krzysztof T. Poźniak, Warsaw University of Technology (Poland)

\section{DSP and Radar Imaging}

Conference Chair

Krzysztof Kulpa, Warsaw University of Technology (Poland)

Symposium Program Committee

Tomasz Adamski, Warsaw University of Technology (Poland)

Chris Baker, University College London, London (United Kingdom)

Marek Banaszkiewicz, Space Research Center of Polish Academy of Sciences, Warszawa (Poland)

Michał Borecki, Warsaw University of Technology (Poland)

Zbigniew Czekała, RADWAR S.A., Warsaw (Poland) 
Jan Domin, Rzeszów University of Technology (Poland)

Andrzej Domański, Warsaw University of Technology (Poland)

Antoni Grzanka, Warsaw University of Technology (Poland)

Krzysztof Holejko, Warsaw University of Technology (Poland)

Stanisław Jankowski, Warsaw University of Technology (Poland)

Leszek Jaroszewicz, Military Academy of Technology, Warsaw (Poland)

Zbigniew Jaroszewicz, Institute of Applied Optics, Warsaw (Poland)

Kazimierz P. Jedrzejewski, Warsaw University of Technology (Poland)

Adam Kawalec, Military University of Technology, Warsaw (Poland)

Ryszard Kisiel, Warsaw University of Technology (Poland)

Wiesław Klembowski, Telecommunication Research Institute, Warsaw (Poland)

Krzysztof Kulpa, Warsaw University of Technology (Poland)

Konstantin Lukin, Institute of Radiophysics \& Electronics, Kharkov (Ukraine)

Lech Mankiewicz, Center of Theoretical Physics, Polish Academy of Sciences, Warsaw (Poland)

Bhaskar Mukherjee, DESY, Hamburg (Germany)

Jan Ogrodzki, Warsaw University of Technology (Poland)

Leszek Opalski, Warsaw University of Technology (Poland)

Jerzy Pietrasiński, Military University of Technology, Warsaw (Poland)

Krzysztof T.Poźniak, Warsaw University of Technology (Poland)

Michal Ramotowski, ELHEP Laboratory, Warsaw University of Technology (Poland)

Marek Sadowski, Sołtan Institute for Nuclear Studies, Świerk (Poland)

Jacek Sekutowicz, DESY, Hamburg (Germany)

Edward Sędek, Industrial Institute of Telecommunications, Warsaw (Poland)

Stefan N. Simrock, DESY, Hamburg (Germany)

Tomasz Starecki, Warsaw University of Technology (Poland)

Małgorzata Suchańska, Kielce University of Technology (Poland)

Mirosław Świercz, Białystok University of Technology (Poland)

Sergio Tazzari, University of Rome, Tor Vergata (Italy)

Jerzy Weremczuk, Warsaw University of Technology (Poland)

Tomasz R.Wolinski, Warsaw University of Technology (Poland)

Jan Wójcik, University of Maria Curie-Skłodowska, Lublin (Poland)

Waldemar Wójcik, Lublin University of Technology (Poland)

Grzegorz Wrochna, Sołtan Institute for Nuclear Studies, Warsaw (Poland) and CERN, Geneva (Switzerland)

Felix Yanovsky, National Aviation University, Kiev (Ukraine) 
Session Chairs

1 Apparatus for Optical and Gamma-Ray Astrophysical Observations

Grzegorz Wrochna, Soltan Institute for Nuclear Studies, Swierk (Poland) and CERN Geneva (Switzerland)

Lech Mankiewicz, Center for Theoretical Physics, Polish Academy of Sciences, Warsaw (Poland)

2 FLASH Laser and European X-Ray Laser Development

Ryszard S. Romaniuk, Warsaw University of Technology (Poland)

Krzysztof T. Poźniak, Warsaw University of Technology (Poland)

3 Superconductive Accelerator Technology for Free Electron Laser and High Energy Photon Physics

Ryszard S. Romaniuk, Warsaw University of Technology (Poland)

Marek Sadowski, Soltan Institute for Nuclear Studies, Swierk (Poland)

Sergio Tazzari, University of Rome, Tor Vergata (Italy)

Bhaskar Mukherjee, DESY, Hamburg (Germany)

4 Photoacoustics and Ultrashort Pulse Technology

Tomasz Starecki, Warsaw University of Technology (Poland)

5 Optical Fiber Technology and Measurements

Dominik Dorosz, Białystok University of Technology (Poland)

6 Optical Fiber Applications

Michał Borecki, Warsaw University of Technology (Poland)

$7 \quad$ Nanomaterials and Material Research for Photonics and Electronics

Stanisław Jankowski, Warsaw University of Technology (Poland)

8 Toward Optical and Quantum Cryptography

Tomasz Adamski, Warsaw University of Technology (Poland)

9 Medical X-ray Accelerators and Biomedical Applications

Antoni Grzanka, Warsaw University of Technology (Poland)

Ryszard Kisiel, Soltan Institute for Nuclear Research, Swierk (Poland) and Warsaw University of Technology (Poland)

10 WARMER Program - Sensory Networks for Water Management/Preservation and Environmental Protection

Leszek Opalski, Warsaw University of Technology (Poland)

Andrzej Filipkowski, Warsaw University of Technology (Poland)

11 Image Processing

Bohdan Butkiewicz, Warsaw University of Technology (Poland)

Jaroslav Cechak, University of Defense, Brno (Czech Republic) 
12 Passive and Active Radar Imaging

Krzysztof S. Kulpa, Warsaw University of Technology (Poland) Joachim Schiller, FGAN (Germany)

13 Signal Processing

Mirosław Świercz, Białystok University of Technology (Poland)

Abdel-Rahman Kamel Al-Qawasami, Philadelphia University (Jordan)

14 Radar Technology

Cezary Szczepański, Telecommunications Research Institute, Warsaw (Poland)

Felix Yanovsky, National Aviation University, Kiev (Ukraine)

15 Optical and Radiofrequency Technology

Adam Kawalec, Military University of Technology, Warsaw (Poland)

Anna Dzvonkovskaya, Hamburg University of Technology, Hamburg (Germany)

16 Optical Measurements

Dariusz Litwin, Institute of Applied Optics, Warsaw (Poland)

Jacek Galas, Institute of Applied Optics, Warsaw (Poland)

17 Algorithms for Data Processing

Tomasz R. Wolinski, Warsaw University of Technology, Warsaw (Poland) Małgorzata Suchańska, Kielce University of Technology (Poland) 


\title{
Wilga-Jachranka 2007 Conference Organizing Committee
}

\author{
Organizing Committee Chair \\ Dominik Rybka, PERG-ELHEP Laboratory, IES, Warsaw University of \\ Technology (Poland) (drybka@elka.pw.edu.pl) \\ Jachranka Conference Committee Staff Coordinator \\ Krzysztof S. Kulpa, DSP and Radar Imaging Laboratory, IES, Warsaw \\ University of Technology (Poland) (K.Kulpa@ise.pw.edu.pl)
}

Director of WUT WILGA Resort

Maria Piłka, Warsaw University of Technology (Poland)

Committee Staff Coordinator

Krzysztof T. Poźniak, PERG-ELHEP Laboratory, IES, Warsaw University of Technology (Poland) (pozniak@ise.pw.edu.pl)

Organizing Committee Members

Jacek Misiurewicz, DSP and Radar Imaging Laboratory, IES, Warsaw University of Technology (Poland) (jmisiure@elka.pw.edu.pl)

Maciej Linczuk, PERG-ELHEP Laboratory, IES, Warsaw University of Technology (Poland) (m/linczuk@elka.pw.edu.pl)

Kamil Maj, PERG-ELHEP Laboratory, IES, Warsaw University of Technology (Poland) (k.maj@elka.pw.edu.pl)

Piotr Samczyński, Telecommunication Research Institute (Poland) (psamczynski@pit.edu.pl)

Jarosław Szewiński, PERG-ELHEP Laboratory, IES, Warsaw University of Technology (Poland) (j.szewinski@elka.pw.edu.pl)

Marcin Smelkowski, PERG-ELHEP Laboratory, IES, Warsaw University of Technology (Poland) (m.smelkowski@elka.pw.edu.pl)

Michał Ramotowski, PERG-ELHEP Laboratory, IES, Warsaw University of Technology, Student Mentor, PERG-ELHEP Research Group Majordomo (Poland) (mira@op.pl)

\section{PERG-ELHEP ISE PW Laboratory Graduated Students}

Lukasz Dymanowski, Kamil Lewandowski, Tomasz Grzywna, Pawel Drabik, Marek Wilczewski, Tomasz Stanislawski, Jakub Glowka, Mateusz Macias, Tomasz Klonowski, Michal Ladno, Michal Wlodarczyk, Robert Piotrkowicz, Piotr Sitek, Lukasz Koniusz, Piotr Obroslak, Andrzej Cichocki, Stefan Korolczuk, Janusz Majnert, Grzegorz Kasprowicz

DSP ISE PW Laboratory Students

Magda Purchla, Marek Kuźniak, Wojtek Kulka, Mateusz Malanowski, Bartek Dawidowicz 
Proc. of SPIE Vol. 6937 693749-24

Downloaded From: https://www.spiedigitallibrary.org/conference-proceedings-of-spie on 25 Apr 2023 Terms of Use: https://www.spiedigitallibrary.org/terms-of-use 


\section{Wilga 2007 Conference Organizers}
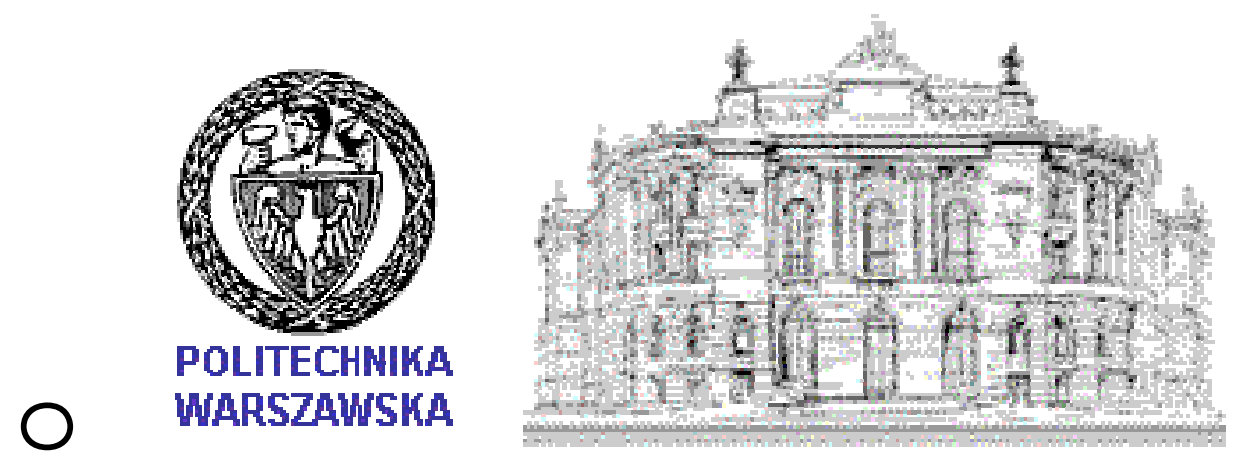

Warsaw University of Technology
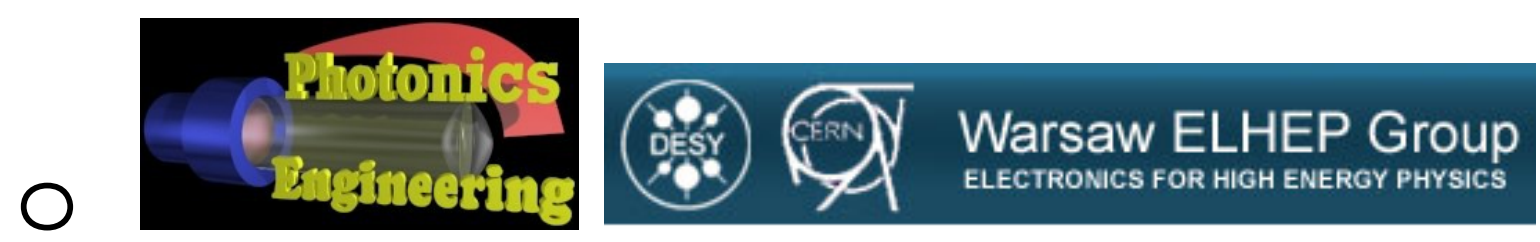

PERG/ELHEP Laboratory (http://www.ise.pw.edu.pl/ rrom),

Institute of Electronic Systems, (http://www.ise.pw.edu.pl),

Faculty of Electronics and Information Technologies (http://www.elka.pw.edu.pl),

Warsaw University of Technology (http://www.pw.edu.pl)

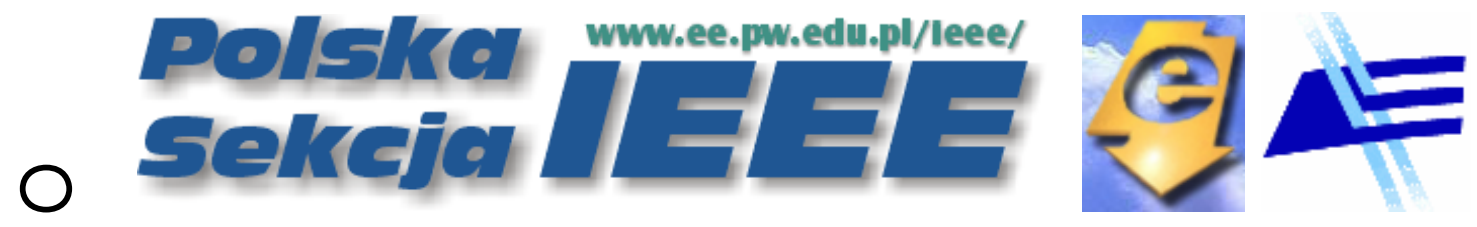

IEEE Student Branch of WUT

IEEE Poland Section (http://www.ee.pw.edu.pl/ieee)

(http://ieee.pl) 


\section{Wilga Symposium Sponsors}

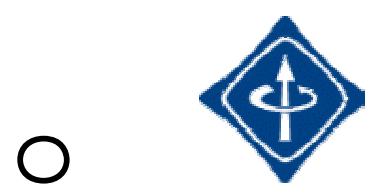

IEEE Poland Section and IEEE Region 8 (SAC\&GOLD)

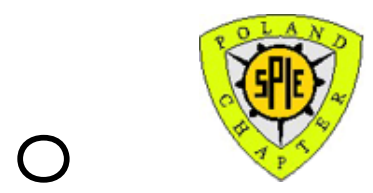

SPIE Poland Chapter

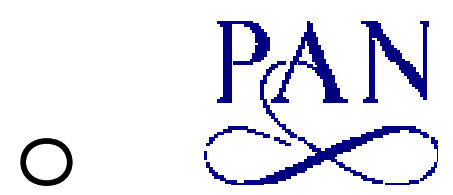

Committee of Electronics and Telecommunications Polish Academy of Sciences

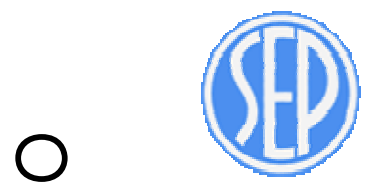

Polish Committee of Optoelectronics Association of Polish Electrical Engineers

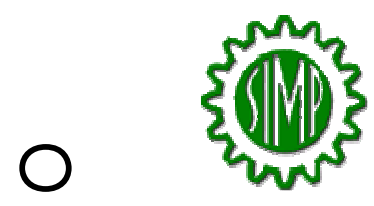

Inter-Association Committee of Electronics, Telecommunication and Information Technologies, Association of Polish Electrical Engineers Association of Polish Mechanical Engineers

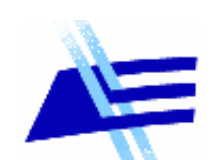

Faculty of Electronics and Information Technologies Warsaw University of Technology

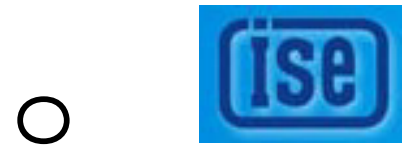

Institute of Electronic Systems, FE\&IT

Warsaw University of Technology 


\section{Wilga Symposium - Cooperating Institutions}

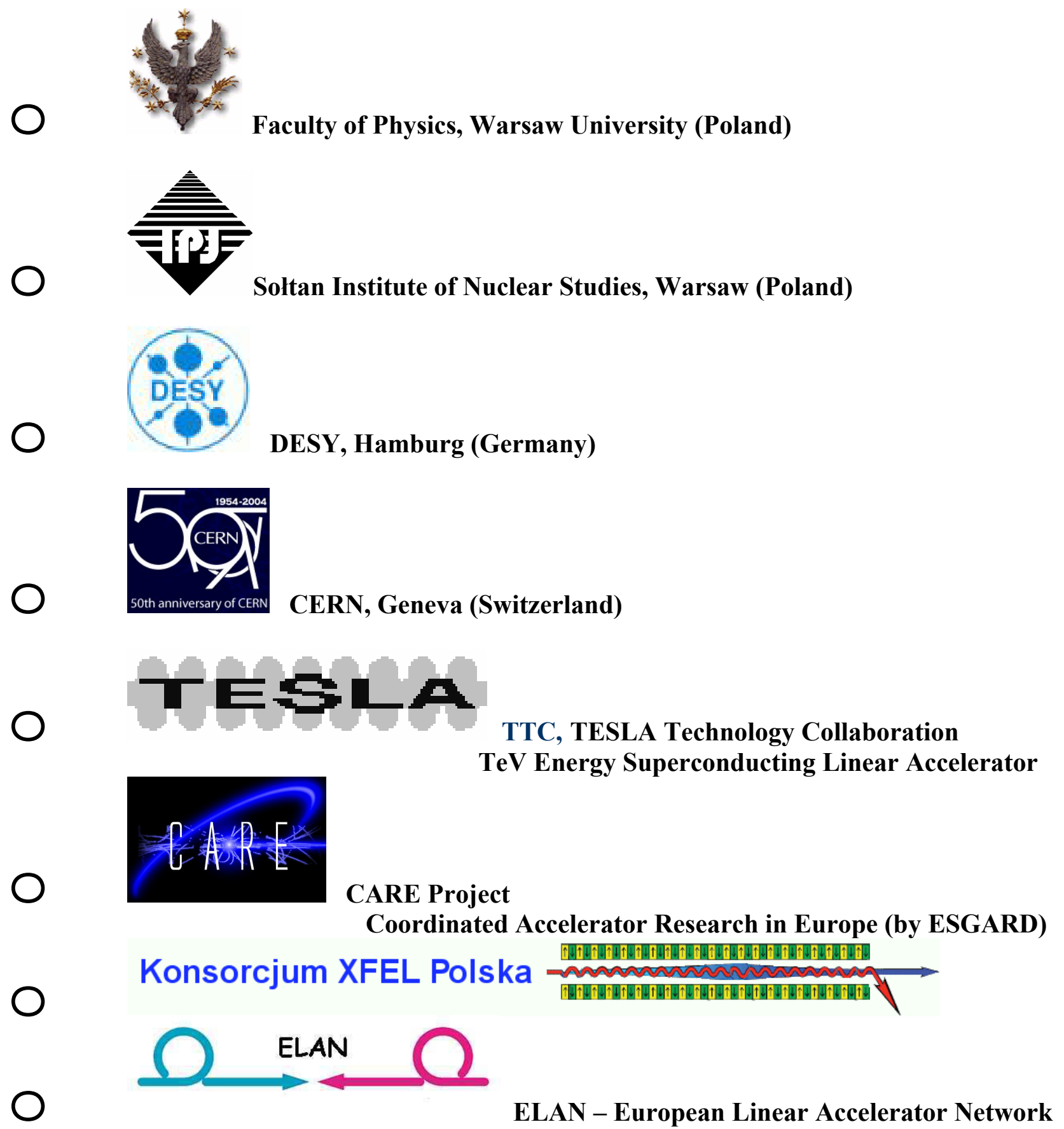


Proc. of SPIE Vol. 6937 693749-28

Downloaded From: https://www.spiedigitallibrary.org/conference-proceedings-of-spie on 25 Apr 2023 Terms of Use: https://www.spiedigitallibrary.org/terms-of-use 


\section{Introduction}

$X X^{\text {th }}$ Jubilee Joint SPIE - IEEE Symposium on Photonics and Electronics for High Energy Physics Experiments, Astronomy, Accelerator Technology and Free Electron Lasers WILGA 2007, 21-27 May (http://wilga.ise.pw.edu.pl)

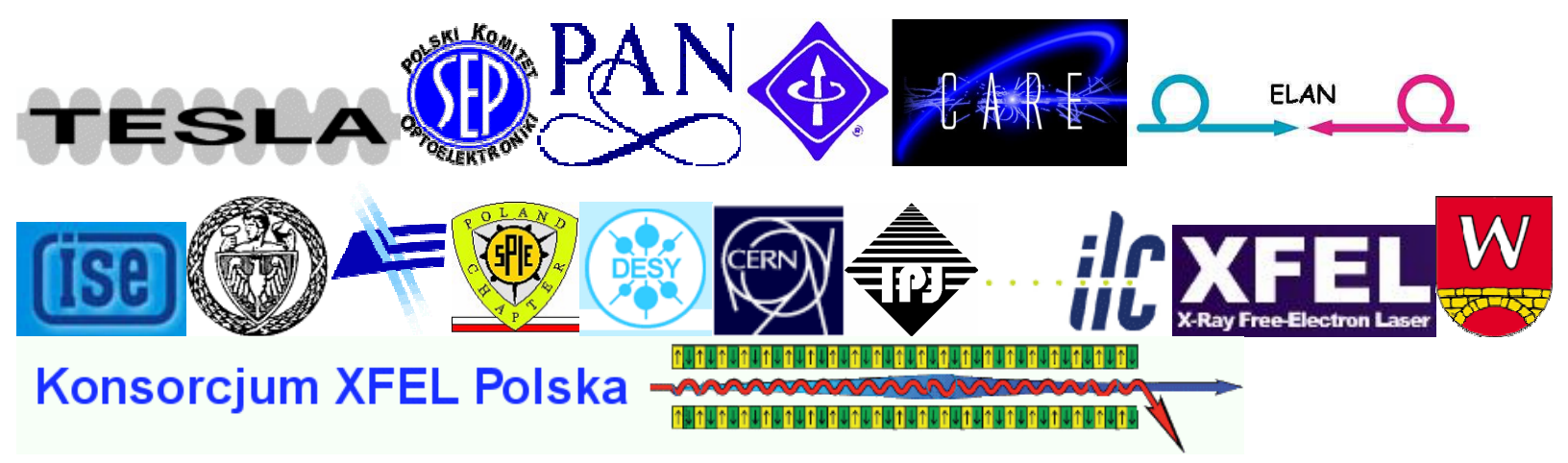

AIMS AND TOPICAL AREA OF SPIE-IEEE WILGA SYMPOSIUM

During the week of 21-27 May, in the WILGA village near Warsaw, a woodland resort owned by the Warsaw University of Technology was a jubilee XXth joint SPIE - IEEE Symposium WILGA 2007. The WILGA Symposium is an international meeting, embracing Poland, neighboring countries and IEEE R8, which is composed of several narrow-subject conferences. The major aim of the Symposium, which has been organized since 10 years now, twice a year, alternately in WILGA (each year at the end of May) and at the Faculty of Electronics and Information Technologies, Warsaw University of Technology (second half of January), is the integration of national and international environment of Ph.D., M.Sc. students and young researchers, who work in the area of advanced applications of photonics and electronics, and particularly in these areas, which require the application of laborious and difficult modeling methods, simulation, identification, implementation and testing of components, devices and systems.

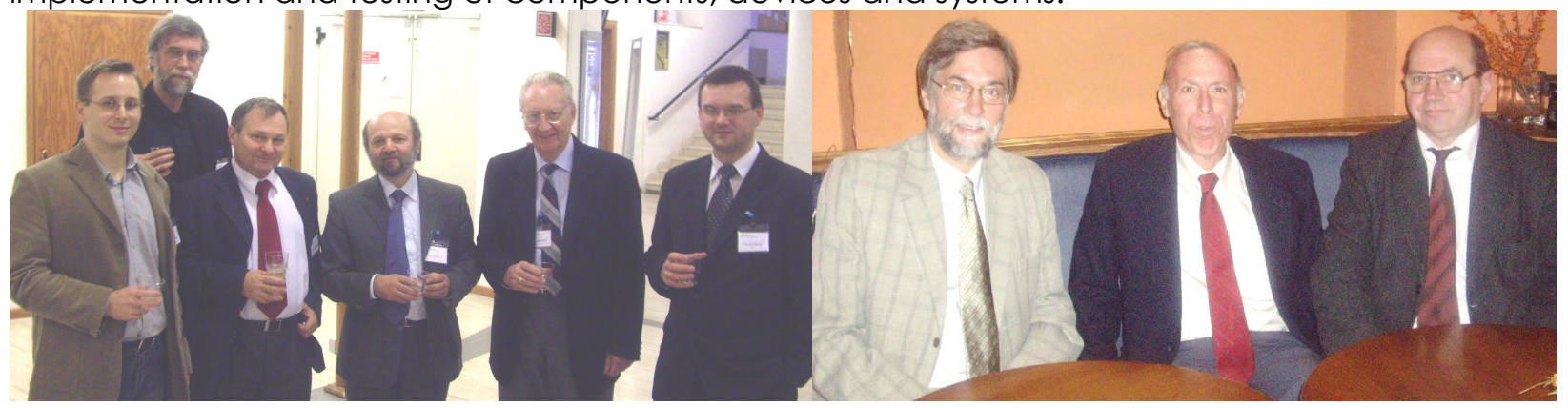

LEFT: CARE Annual Meeting in INFN Frascati; from left P. Strzyzewski, Prof. R. Romaniuk, Prof. A. Napieralski, Dr. R. Aleksan, Prof. M. Sadowski, Dr. M.Grecki; RIGHT: A visit from Prof. Abraham Katzir of Tel Aviv Univ. to SPIE Poland Chapter, from left: Prof. R. Romaniuk, Prof A. Katzir, and Prof A. Domanski. 
The major topical track of the Symposium concerns the newest developmental trends of photonics, electronics and information technologies in their most demanding practical applications (such as military, astronomy, fundamental research). The aim of the Symposium is, not the presentation of inspiring engineering work (though a number of such presentations are included in the program as an illustration of the developmental processes) but, a strong emphasis on contemporary methods of generation of intellectual property values in the abovementioned subjects. This term IP - Intellectual Property - and combined area become more and more of an elementary foundation of the society basing on knowledge. Production and further development of a product is a separate subject. The main task here is creation of an advanced product consisting, in terms of an aggregated invested effort, in $80 \%$ from nonmaterial values (software) and only in $20 \%$ from strictly material values (hardware). We assume here that the most interesting is undertaking big tasks, where the accumulated effort is above 10 person-years (PY) and sometimes is bigger than 100 PY or more. The costs of such tasks is very big, of the order of millions Euro. The results are also of considerable impact on current technologies.

One fundamental area of activity for the SPIE-IEEE WILGA Symposium are general questions of the following kind: "How to undertake such big and advanced projects, of a very big IP load, in a university environment? Projects of this kind are offered, especially within the frames of European Research Area (ERA). We have to reach for young scientists, a considerable number of them. The ability to efficiently manage and coordinate the effort, to generate IP, of tens of M.Sc. and Ph.D., students and young researchers, is a prerequisite for undertaking such big projects by university teams. These coordination efforts take place in typical university conditions under the continuous flow of research workers and exchange of students' generations through the research team involved in a concrete project. A core of the team are faculty members, external experts from research governmental institutions or industry and Ph.D. students, who were previously cooperating with the same group while realizing their M.Sc. theses, thus bound with this group for a longer period spanning even for 6-8 years. Additionally, in the case of small teams, which are not competent in the whole researched area of the project, it is necessary to create flat, sufficiently big, research structures of inter-laboratory, inter-departmental, interinstitutional, inter-university, and international character. Covering the whole area of the required competence is a target to create a flat research structure consisting mainly of young researchers. This target emphasizes that some university teams show considerable inertia against these integration and flexible reconfiguration processes.
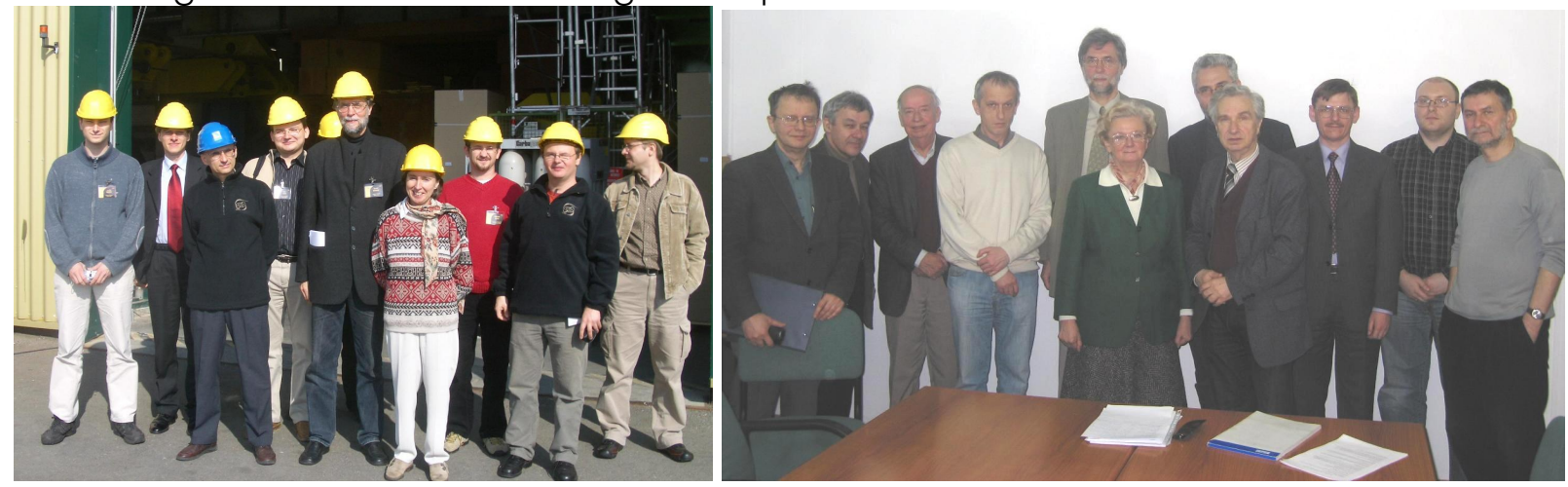

LEFT: Members of the PERG/ELHEP WUT ISE Group in front of the CMS hall in CERN with Prof. ClaudiaElisabeth Wulz from the Institute of Physics, Austrian Academy of Sciences (in the middle); RIGHT: A group of initiators of Polish Consortium for Human Resources training for Nuclear Industries, Faculty of Physics, Warsaw Univ. 
Traditionally debated applications of photonics, electronics and information technologies during WILGA, and relevant to the abovementioned problems are: algorithms of remote control for hardware, architecture and algorithms for large distributed measurement networks, simultaneous processing and multilevel triggering of large amounts of measurement data in algorithmically complex systems, modeling of phenomena, objects and systems, identification of objects and systems, algorithms for complex finite state machines, modeling of robotic management of experiments, etc. A unique feature of SPIE-IEEE WILGA Symposium are late night debate sessions, sponsored by IEEE, and devoted to management of large and long lasting research projects carried out by large and young university teams.

A research cycle in the large photonics and electronics systems under debate is the following: a proprietary, nonmaterial IP input of large value is being inbuilt into a material background. The hardware is composed of the following components: processors of the major three different types - CPU, FPGA and DSP, supplemented by memory resources, I/O buffers, data type converters and fast data links - internal and external. Optimal hardware structure of data processing is proportionally changing with the development of system components. However, the largest value of the system is attributed to successive programming layers: from the definition of hardware solution, via functionality modeling, object modeling, via intermediate software communications layers, middleware, to layers of the graphical user's interface. 


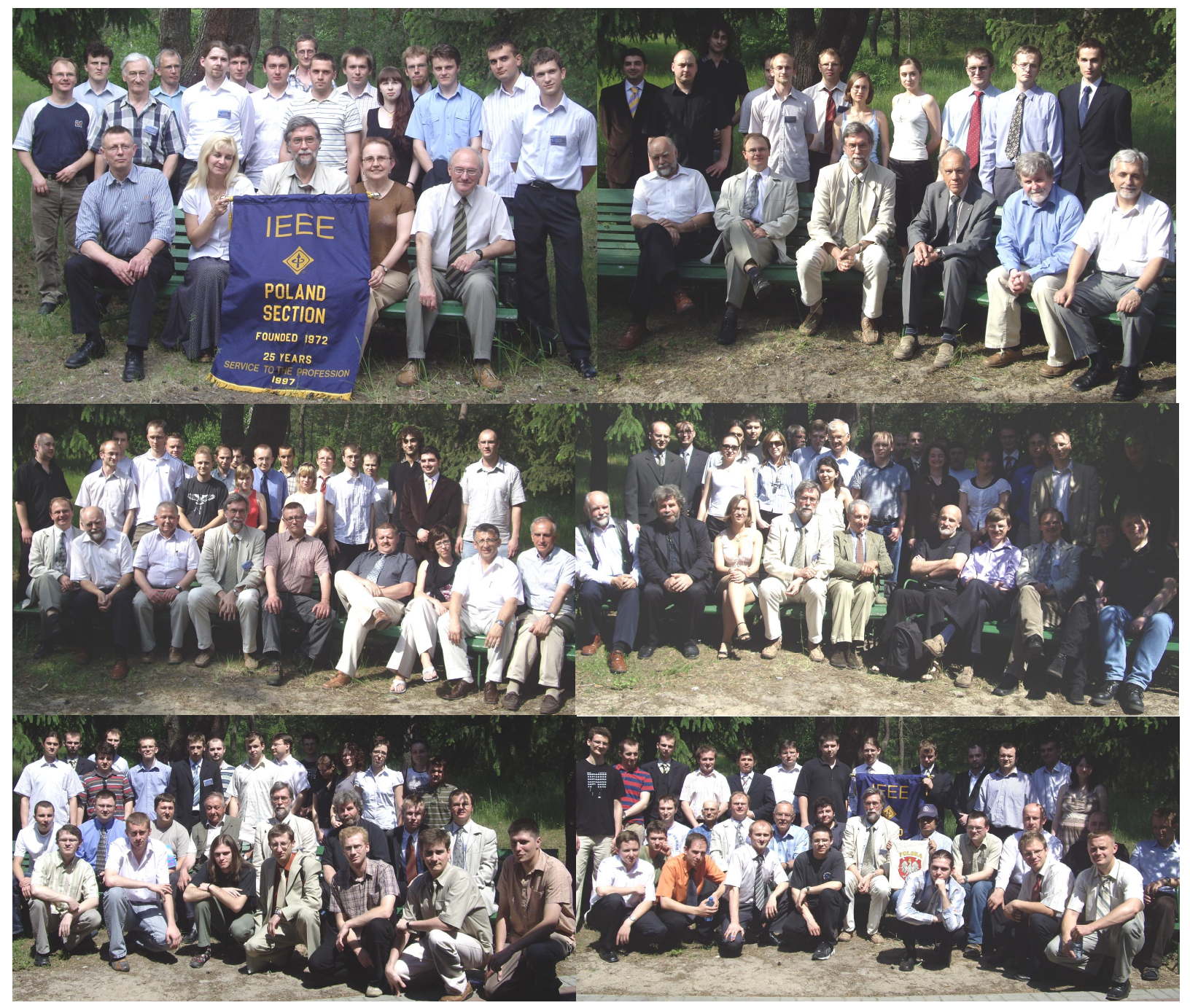

Photographs of the participants of XX IEEE-SPIE WILGA Symposium on Photonics Applications taken during successive days. Professors participating in the XX WILGA Symposium: Prof. Zbigniew Jaroszewicz-Institute of Applied Optics, Warsaw; Prof. Małgorzata Suchańska - TUV of Kielce; Prof. Jan Domin - TUV of Rzeszów; Prof. Andrzej Filipkowski, Prof. Leszek Opalski, Prof. Jan Ogrodzki, Prof. Tomasz Woliński, Prof. Tadeusz Morawski, Prof. Antoni Grzanka, Prof. Tomasz Adamski, Prof. Ryszard RomaniukWarsaw Univ. of Technology; Prof. Jan Wójcik - UMCS Lublin; Prof. Leszek Jaroszewicz -WAT Warsaw; Prof. Marek Sadowski, Prof. Grzegorz Wrochna - IBJ Świerk; Prof. Sergio Tazzari - Tor Vergata Univ. Roma; Dr. Bhaskar Mukherjee - DESY Hamburg; Prof. Michał Różyczka-CAMK Warsaw; Prof. Wojciech Plandowski- Warsaw University.

\section{PARTICIPANTS, ORGANIZERS, PATRONS AND SPONSORS OF SPIE-IEEE WILGA SYMPOSIUM}

For several years now, the Symposium has been gathering over 200 (and during the best years more than 300) M.Sc., D.Sc., students and young researchers from this country and internationally. Frequently enough, the Symposium hosts representatives of such research organizations like CERN, DESY, INFN, CEA, IN2P3, FNAL and European technical universities. Similarly to previous years, considerable delegations of technical universities attended topical 
sessions organized by themselves. WILGA 2007 Symposium hosted, among others, representatives from: Warsaw, Poznań, Opole, Gdańsk, Bydgoszcz, Zielona Góra, Kraków, Kielce, Lublin, Białystok, Łódź, Rzeszów, Gliwice, Hamburg, Rome, Geneva, Sofia. There were presented more than 170 papers in WILGA sessions and over 50 in Jachranka sessions.

The WILGA Symposium is organized under the high patronage of international professional organizations IEEE [Www.ieee.org] and SPIE [www.spie.org] and their Poland Sections [ieee.pl], [spie.pl], international institutions CERN in Geneva [www.cern.ch] and DESY in Hamburg [www.desy.de], and national institutes: Association of Polish Electrical Engineers - Polish Committee of Optoelectronics [www.sep.com.pl], Polish Academy of Sciences - Committee of Electronics and Communications [www.pan.pl], Warsaw University of Technology [www.pw.edu.pl] - Faculties of Physics [www.if.pw.edu.pl], Mechatronics [www.mech.pw.edu.pl] and Electronics and Information Technologies [www.elka.pw.edu.pl], Sołtan Institue of Nuclear Research in Świerk [www.ipj.gov.pl].

IEEE-SPIE WILGA Symposium is sponsored by the European FP6 programs run by the European Steering Committee of Accelerator Research and Development ESGARD [esgard.lal.in2p3.fr] CARE - Coordinated Accelerator Research in Europe [care.lal.in2p3.fr] and ELAN - European Linear Accelerator Network [elan.desy.de]. Subject area of WILGA is combined with large research programs and the institutions which carry them: XFEL- European X-Ray Free Electron Laser [http://xfel.desy.de/] and Polish XFEL Consortium [http://xfel.pl/], ILC- International Linear Collider [linearcollider.org] and TESLA Consortium [http://tesla-new.desy.de/], LHC- Large Hadron Collider [cern.ch/lhc], CMS- Compact Muon Solenoid [cms.cern.ch]. The logos of abovementioned organizations and programs, together with WILGA Village and Commune crest, our host of WILGA meetings, were displayed in the heading of this report.

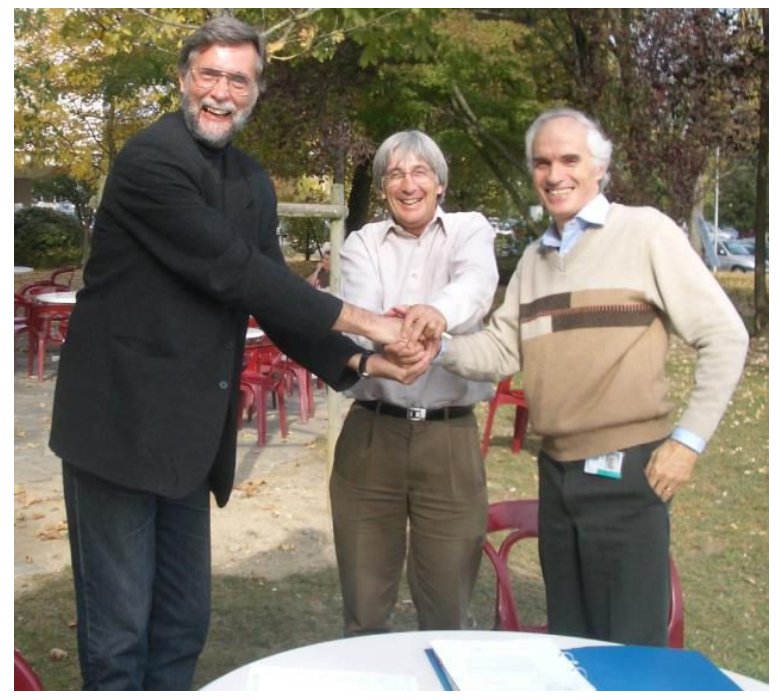

CERN, Geneva, 10, 2005, A meeting on cooperation. From right: Dr. Lovis Rinolfi, Dr. Jean Pierre Delahaye, CLIC Collaboration, Prof. R. S. Romaniuk,

WILGA Symposium is organized by the PERG/ELHEP Laboratory [http://tesla.desy.de/ elhep/] of the Institute of Electonic Systems of Warsaw University of Technology (WUT) [Www.ise.pw.edu.pl]. This year, the Chairmen of the WILGA 2007 Organizing Committee were Ph.D. students Mr. 
Dominik Rybka and Jarosław Szewiński, supported by around 20 PERG/ELHEP Group students. The co organizers of the WILGA Symposium are all IEEE and SPIE Student Branches in this country.

The Patronage Committee of WILGA Symposium consists of chiefs of the patronage institutions: prof. Jan Dorosz-Director of Ph.D. Study of Białystok Univ. of Technology; Prof. Bogdan Galwas Dean of the Faculty of Electronics and Information Technology, Warsaw Univ. of Technology; Prof. Henryk Fiedorowicz - Director of the Institute of Optoelectronics, Military Academy of Technology; Prof. Wiesław Woliński, member of PAS, Chair of The Committee of Electronics and Communications, PAS; Prof. Tomasz Woliński - President of Polish Chapter of SPIE; Prof. Andrzej Pacut - President of Poland Section of IEEE; Prof. Grzegorz Wrochna - Director of The Sottan Institute for Nuclear Problems in Świerk; Prof. Jerzy Szabatin - Director of the Institute of Electronic Systems, WUT; Prof. Marian P. Kaźmierkowski - Director of the Institute of Control and Industrial Electronics, WUT; Dr. Jacek Galas and Dr. Mariusz Litwin -vice-directors of the Institute of Applied Optics. The Patronage Committee guarantees the highest level of the research reports presented in WILGA. The Scientific Committee of WILGA consists of professors present personally at the Symposium. The Committee reviews the papers and accepts them for publishing. Members of WILGA 2007 Scientific Committee are named under the photos opening this report.

\section{MEDIA PATRONAGE AND PUBLICATIONS OF WILGA SYMPOSIUM}

Media patronage on the WILGA meetings of young researchers has a monthly research journal ELEKTRONIKA issued by the Association of Polish Electrical Engineers [http://www.sigma-not.pl]. Internationally, WILGA publishes its reports in IEEE Region 8 News [http://www.ewh.ieee.org/reg/8/news/].

The proceedings of WILGA are published in ELEKTRONIKA, Electronics and Telecommunication Quarterly by Polish Academy of Sciences. Several times these were special issues of the journals. Internationally, WILGA publishes in Proceedings of SPIE and in such journals like MSTMeasurement Science and Technology [http://www.iop.org/EJ/journal/MST] and NIM- Nuclear Instrumentation Methods [www.elsevier.com/locate/nima]. A considerable success of WILGA 2006 was preparing almost 20 papers for a special issue of the MST Journal. With the works of WILGA there is combined an exceptional publication about the FLASH Laser. It was written by XFEL Consortium in co authorship of several persons from the PERG/ELHEP Laboratory and published in the June Issue 2007 of the NATURE Photonics [http://www.nature.com/nphoton].

Together with a dynamic development of the web, the publication methods of conference proceedings undergo a considerable evolution. SPIE resigns from the printed versions of the worldwide recognized, famous yellow photonics volumes, Proc. SPIE. Instead, similarly to other big international professional societies like IEEE (Explore web publication system), and OSA Optical Society of America (Optics InfoBase web publication system), all SPIE Proceedings are published on a complex Internet technical publication database called SPIE Digital Library [http://spiedl.org/]. Publications in all these web based systems are fully indexed as they were in printed versions.

\section{TOPICAL SESSIONS OF SPIE - IEEE WILGA SYMPOSIUM}

The IEEE-SPIE WILGA Symposium lasts traditionally the whole week, from Monday in the morning till Sunday evening. It is always the last week of May. WILGA consists of topically adjacent research conferences, which are subdivided to topical sessions. Only exceptionally, there are organized parallel sessions. An organizer of a topical session is a recognized expert in this field. She or he invites young scientists to the session, who are obliged to prepare and present original 
papers from their own work. WILGA 2007 consisted from the following topical tracks (called by us conferences): Web Engineering; Photonics Applications; Signal Processing and Radar Technology; Photonics and Electronics Systems in High Energy Physics Experiments, Astronomy and Accelerator Technology.

IEEE-SPIE WILGA 2007 was organized in the same time in two places: WILGA and Jachranka. A Conference on DSP and Radar Technology was organized in Jachranka by Dr. Krzysztof Kulpa from WUT. The remaining WILGA sessions were organized by the following persons: Col. Dr. Zbigniew Patron, WAT - Lasers and Applications; Prof. Antoni Grzanka, WUT - Biomedical Instrumentation; Dr. Ryszard Kisiel, WUT and IPJ - Packaging and Hybrid Integrated Circuit Technology; Dr. Michał Borecki, WUT - Optoelectronic Sensors; Dr. Jacek Galas and Dr. Dariusz Litwin, INOS - Applied Optics; Dr. Tomasz Starecki, WUT - Fast Pulse Electronics and Photoacoustics; Dr. Jerzy Weremczuk, WUT - Smart Sensors; Prof. Jan Domin, Rzeszów Univ. Technology - Spectrographic Techniques, Prof. Tomasz Woliński, Prof. Andrzej Domański, WUT Photonic Optical Fibers; Dr. Stanisław Jankowski, WUT - Optimal Learning Systems; Prof. Leszek Opalski, WUT - European Programs SEWING and WARMER; Prof. Lech Mankiewicz, CTF PAS, Prof. Grzegorz Wrochna, IPJ - Program Pi-of-The-Sky; Dr. Ryszard Kisiel, WUT and IPJ - Linear Accelerators; Prof. Marek Sadowski, IPJ - Thin Film Technology; Prof. Jan Dorosz, Białystok Univ. Technology - Optoelectronics and Numerical Methods; mgr Aneta Michalkiewicz, Student Section of SPIE at WUT - Applied Optics; Prof. Tomasz Adamski, WUT - Information Safety; Dr. Bhaskar Mukherjee, DESY - European X-Ray FEL - A Light of the Future. Ph.D. Students of PERG/ELHEP IES Laboratory, under the guidance of Dr. Krzysztof Poźniak, Dr. Maciej Linczuk and Dr. Michał Ramotowski have organized a few sessions on photonic and electronic systems for the superconductive accelerator technology and free electron lasers.

A special ceremonial session was devoted to the memory of the late professor Bogdan Paczyński. This session was combined with a conference on mysterious GRB and optical flashes of all the sky. Prof. Bogdan Paczyński, member of the Polish Academy of Sciences, was a worldwide precursor of the evolution modeling of certain types of stars. A fascinating lecture about the life and work of Prof. B. Paczyński was delivered by Prof. Michał Różyczka from the Nicolas Copernicus Center of Astronomical Research. Prof. Paczyński was no doubt one of the most famous Polish scientists. He is a laureate of all the most important international astronomical research awards. He was a few times a candidate for the Nobel Prize in Astronomy. The paper In Memoriam of Prof. Bogdan Paczyński is published in Proc. SPIE WILGA 2007 (paper CID \#693701).

Each WILGA Symposium organizes traditionally an artistic-humanistic session as a supplement to the dominating technical sessions. Previous sessions of this kind concerned, for example, sociology of the Internet. This year, second time in row, the subjects are palindromes, because of exceptional activity in this area by Prof. T. Morawski from WUT, usually an expert in the electromagnetic field theory. He has recently published third book on the subject and has written a collection of palindromes devoted to students and WILGA Symposium. The session consisted of two lectures: Palindromes in Mathematics by Prof. W. Plandowski from Warsaw University and History of Palindromes in Polish Fine Literature by Prof. T. Morawski [http://www.palindromy.pl/]. 


\section{EUROPEAN X-RAY FREE ELECTRON LASER - XFEL}

On 30th January, almost twenty national research institutions signed an agreement to establish the Polish Consortium of XFEL. The aim of the Consortium is to coordinate the research work and construction efforts as well as exploitation of the E-XFEL. XFEL Poland G.M.B.H. will be established soon to be a part of the E-XFEL G.m.B.H. enterprise. These firms will be the owners of the XFEL machine.

\section{Signatories of the XFEL Consortium Poland}

Institute of Physics, Polish Academy of Sciences

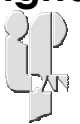

Niewodniczańsk Institute of Nuclear Physics, Polish Academy of Sciences, Kraków

Mechanical and Energetics Faculty, Wrocław University of Technology

Andrzej Sołtan Institute for Nuclear Research in Świerk

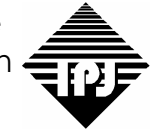

Warsaw University of Technology

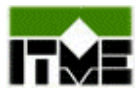

Łódź University of Technology

Technology Materials, Warsaw

Faculty of Physics, Warsaw University

Institute of Electron Technology, Warsaw

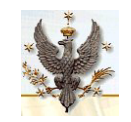

Szczecin University of Technology
Institute of Plasma Physics and Laser Microsynthesis, Warsaw
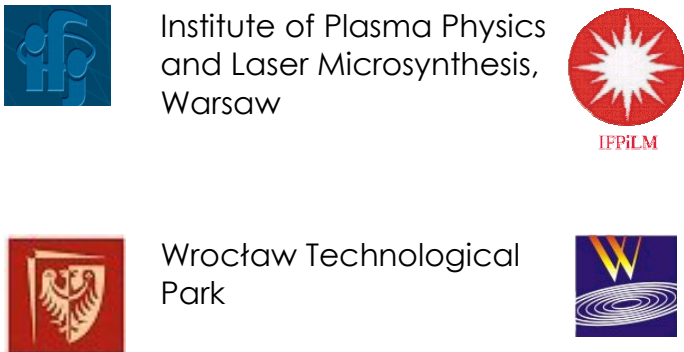

Wrocław Technological Park

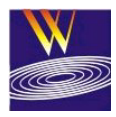

Tele and Radio electronics Institute, Warsaw

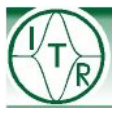

Military Academy of Technology, Warsaw

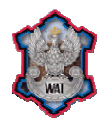

PREVAC sp. z o.o.

Enterprise in Rogów (Fine PREVAC and vacuum technologies)

Faculties of Electrical Engineering, Automation, Information Technology, Electronics and Physics and Applied Informatics, Academy of Mining and Metallurgy, Kraków

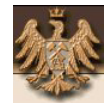

The IEEE-SPIE WILGA Symposium is an official research meeting of the XFEL-Poland. Traditionally, since several years, one of the major topical subjects of WILGA create numerous papers on superconducting accelerator technology and on free electron lasers. A considerable number of researchers in Poland are engaged in building and tests of the FEL. A precursor to E-XFEL is FLASH, a laser currently under reconfiguration and tests. A considerable number of young researchers from Poland are participating in the construction of FLASH. These include representatives of the following institutions: Sottan Institute for Nuclear Research in Świerk, Universities of Technology from Warsaw, Wrocław and Łódź and Warsaw University. These young authors submitted a few tens of contributed papers on this subject to WILGA 2007 Symposium. The papers from FLASH and XFEL sessions will be published in the Proc. SPIE volume from WILGA in the USA. 

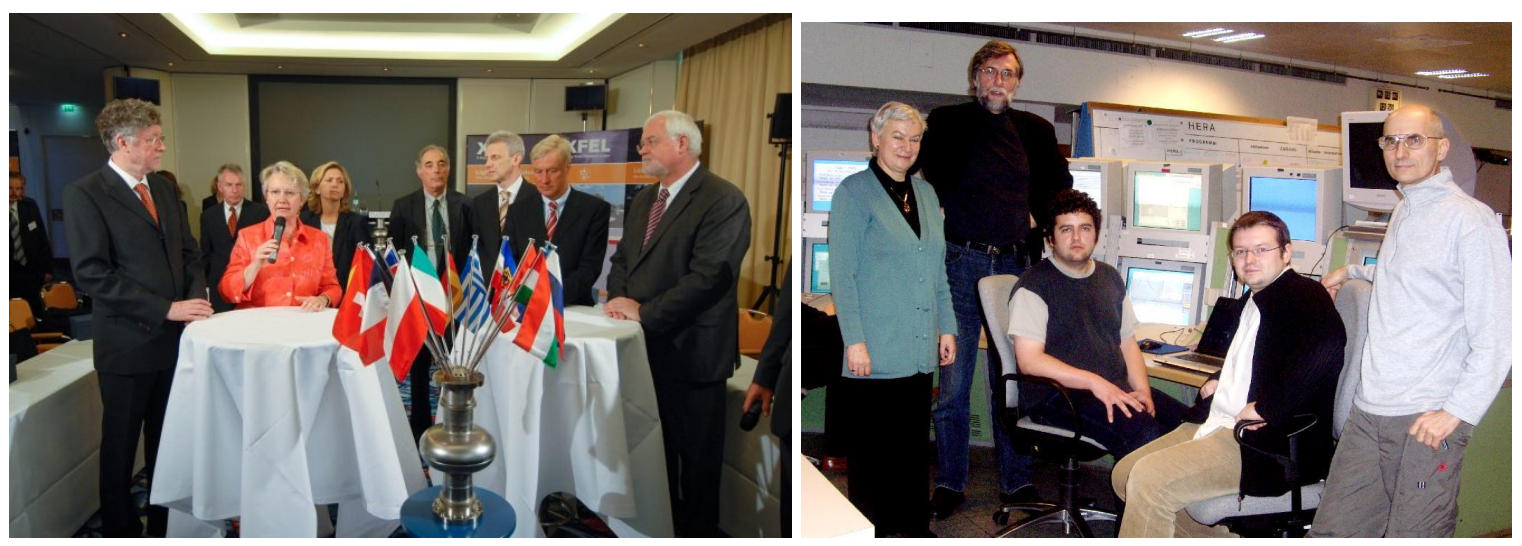

DESY, 5 June 2007: Official opening of the European X-Ray Free Electron Laser. Federal Minister of Research Ms Annette Schavan is speaking; from left DESY Director Prof. Albrecht Wagner, from right Director of XFEL Program Prof. Massimo Altarelli and European Research Commissioner Janez Potocnik. In the foreground there is a single cell niobium resonator (basic component for the SRF TESLA technology accelerator) in which there are positioned the flags of all countries participating in building of the E-XFEL machine: Germany, Denmark, France, Greece, Hungary, Italy, China, Poland, Russia,

DESY, 15 December 2006: A visit to FLASH control facility in DESY by Prof. K. Jabłońska-Ławniczak, the Polish representative in Scientific and Technical Issues Working Group for XFEL. Beside: Prof. R. Romaniuk and Ph.D. students from Warsaw University of Technology and Łódź University of Technology - W. Jałmużna,

W. Cichalewski, T. Czarski. The students are testing new control algorithms for the superconductive liniac and FEL. Influence of various control conditions on the electron and photon beams is investigated. Spain, Sweden, Switzerland and England.

Several days after WILGA Symposium, an official opening of the European XFEL program took place in DESY. A number of representatives from this country participated in this important meeting like representatives of the Ministry of Research (Dr. J. Gierliński) and Polish XFEL Consortium (Prof. K. Jabłońska, Prof $G$. Wrochna), in these a few participants of WILGA Symposium.

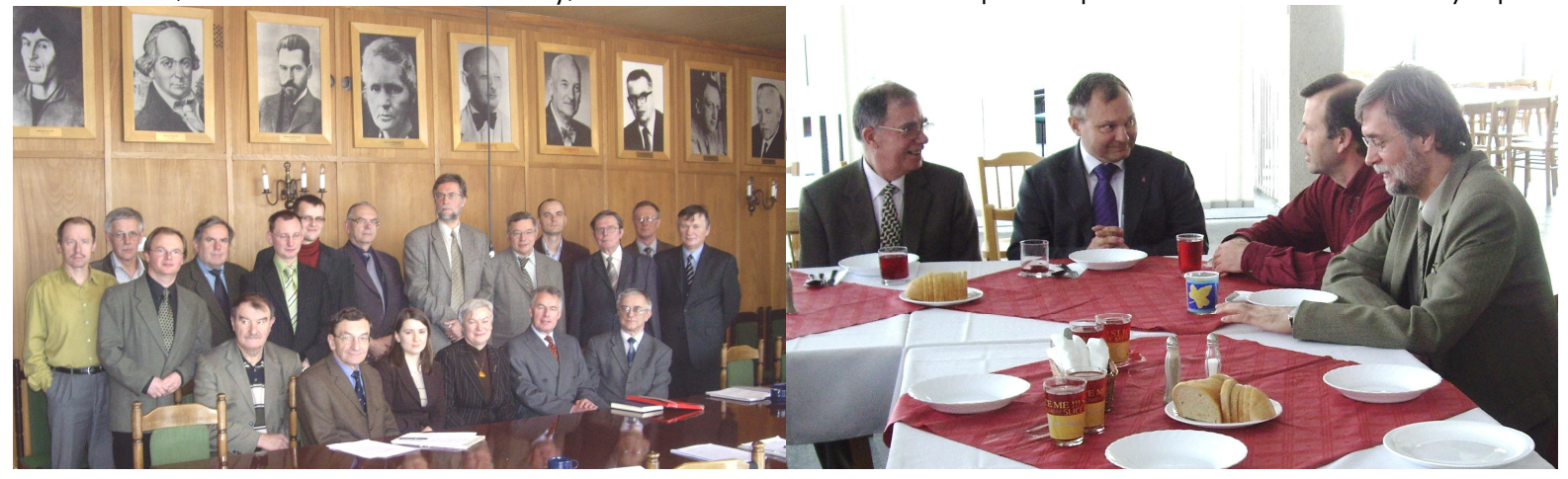

Warsaw, Institute of Physics PAS, 30.01.2007:

Signatories of the Polish XFEL Consortium.

Representatives of the institutions - members of XFEL Poland. Sitting in the middle are

Prof. K. Jabłońska and Dr. J. Gierliński.
Warsaw, WUT, 28.02.2007: Visit of Dr. Oliver Napoly from CEA Saclay, a delegate of ESGARD and ECFA to prepare progam SRF-FP7. From the left: Prof. J. Dobrowolski, Prof A. Napieralski, Dr. O. Napoly, Prof. R. Romaniuk. 


\section{POLAND CHAPTER OF SPIE AND POLAND SECTION OF IEEE}

WILGA 2007 is the last Symposium organized under the patronage of SPIE Poland Chapter. The Chapter has been chaired very successfully from several years by Prof. Tomasz Woliński from WUT. Poland Chapter of SPIE has been acting during the period 1985-2007 as a Registered Society and had a legal personality. SPIE Headquarters, by the Board decision, liquidated regional Chapters from 01.01.2008. SPIE will cooperate directly with national associations of photonics. There were not liquidated regional SPIE Student Chapters. They are active at many universities around the world. Such a Chapter is located also at Warsaw University of Technology, and was one of the organizers of WILGA 2007 Symposium. In order to debate these changes, the Board of SPIE Poland Chapter gathered in WILGA during the Symposium. The continuation of SPIE Poland Chapter will be carried out by, just under organization by local researchers and engineers, the Photonics Society of Poland.

During the SPIE PL Board meeting, the writing these words, was honored by the 2007 Award of the President of SPIE Poland Chapter. The quotation from the award plaque is: "For a substantial contribution to integration of young Polish researchers, and in particular for organization of the jubilee XXth WILGA Symposium on Photonics Applications: Photonics and Web Engineering; Electronics for Astronomy and High Energy Physics Experiments".

The history of WILGA Symposium is an integral part of the history of SPIE Poland Chapter. WILGA has grown up from an exceptionally creative environment of the Chapter. The Chapter was run during the most difficult years by the late Prof. Maksymilian Pluta. The Chapter was undertaking, during these years, wide international initiatives, which seemed then impossible to be realized. Yet, all the dreams of this group of vigorous people were fulfilled. SPIE Poland Chapter in an unprecedented way has integrated nearly the whole national research people active in photonics around such big and brave projects. During the period of 1986-2007 the Chapter has issued alone and in cooperation nearly 200 volumes of the famous photonics series Proceedings of SPIE. These volumes contain around 10,000 research and technical papers, which are a sustained contribution of Polish science and technology into the world research resources. Without the SPIE Poland Chapter it would not have been possible. A spectacular success of the Chapter, not only research but also financial, was the organization of East and Middle European Congress on Optics and Photonics in September 2005. This Congress marked 50th Anniversary of SPIE. The President of SPIE was then Prof. Małgorzata Kujawińska. The cooperation with SPIE Headquarters on this Congress was exceptionally good. 

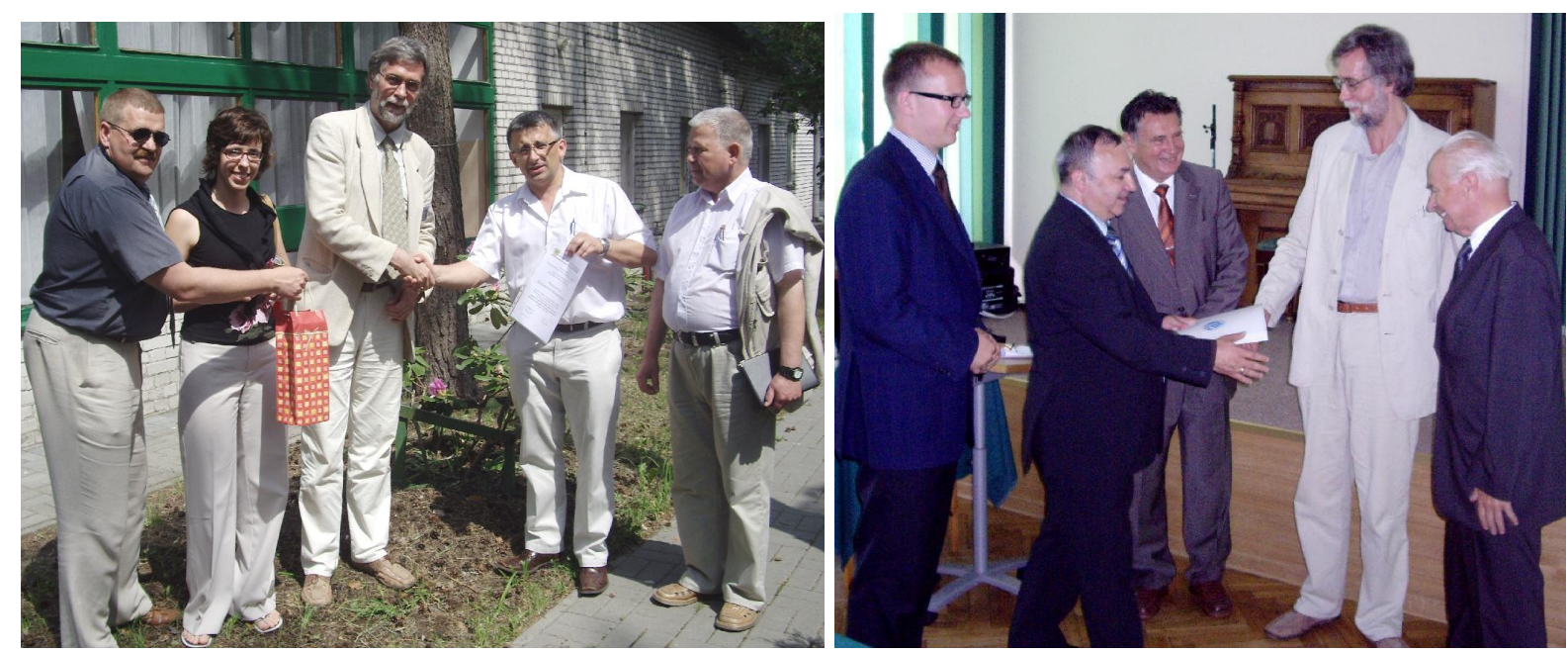

Left: Wilga, 23 May 2007: Meeting of the Board of SPIE Poland Chapter. Prof. Tomasz Woliński hands to Prof. R. Romaniuk the 2007 Annual Award by SPIE Poland Chapter President. From left: Prof. Leszek Jaroszewicz, WAT, - vice-President of the Board, mgr Aneta Michalkiewicz - Chairwoman of SPIE Student Branch at WUT, Prof. Jan Wójcik, UMCS Lublin - Revision Committee of SPIE Poland Chapter. Right: Electrotechnical Institute, Warsaw, 14.06.2007, Prof. Jerzy Barglik, President of SEP-Association of Polish Electrical Engineers hands to Prof R. Romaniuk Professor Pozaryski Prize, besides Prof. Jerzy Klamka-Editor in Chief of ELEKTRONIKA Monthly, Prof. Mieczysław Hering, WUT, Chairman of The Professor Pozaryski Award Chapter.

Without a continuous and generous support from the IEEE Poland Section, the organization of such a big meeting like a multi-conference WILGA Symposium would have not been possible. The M.Sc and Ph.D. students. Organizers of WILGA Symposium, which is very important not only for them but for many young researchers in this country and in this geographical region, count on further support by IEEE Poland Section. The Symposium has to maintain its cyclic character without any interruptions. Students would like to extend their thanks for uninterrupted WILGA support to the successive Presidents of IEEE Poland Section, professors of WUT: Ryszard S. Jachowicz, Marian P. Kaźmierkowski and Andrzej Pacut.

\section{WILGA 2008 SYMPOSIA}

XXI Symposium will be held on 18-20 January 2008 at the Faculty of Electronics and Information Technologies, WUT. The January Symposium is strictly confined topically to the design, construction and testing of of photonic and electronic systems for superconductive RF accelerator technology and HEP experiments.

XXII IEEE WILGA 2008 Symposium will be held on 26 May - 1 June. The organizers, M.Sc. and Ph.D. students of WUT, as each year, warmly invite young researchers to present developments of their theses. In particular, young scientists are invited to share their experiences in now still widening participation in the European Research Framework Programs. The programs create new, young dimensions in the European Research Area (ERA). IEEE-SPIE WILGA Symposium is a unique possibility for Ph.D. students, not only to present their results in international conditions (WILGA is carried only in English, papers are doubly peer reviewed, they provide a considerable number of categorization points for their authors), but also enable comparison of methods and conditions of research work in different, national and international centers. 


\section{WILGA}

Due to a round number jubilee of WILGA young researchers meetings series, below there are some considerations about different WILGAs. All Wilgas are a continuous inspiration to our Symposium.

WILGA - (Oriolus) Golden Oriole is a medium size migrant bird, belonging to passerine family, breeds in northern hemisphere, winters in tropics. The male is striking in the typical oriole black and yellow plumage. It spends Summer, among other places, in Poland. Usually resides high in the canopy. Very shy. Feeds on fruit and insects. The presence is revealed with beautiful fluting. Sings frequently just before the rain starts falling. WILGA Symposium participants listened frequently to Oriole concerts.

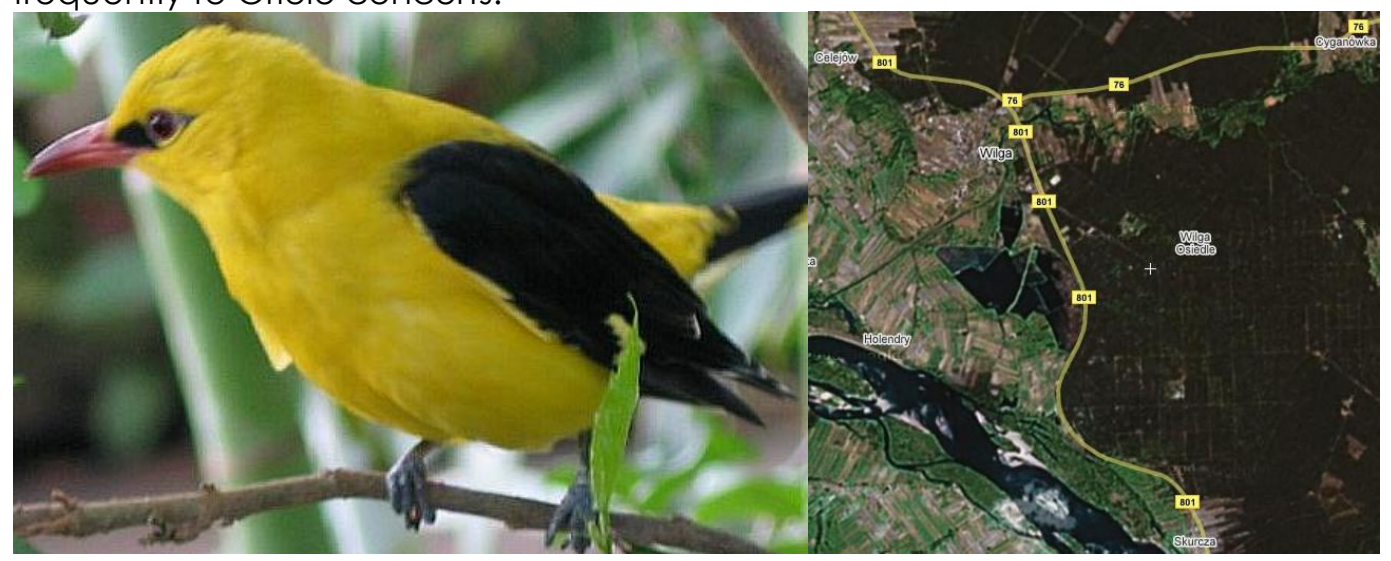

WILGA - (Wet River) a river in the Mazowia Voivodeship, length $67 \mathrm{~km}$, area $570 \mathrm{~km}^{2}$, right inflow to Vistula. The sources in vicinity of Żelechowa (where it is connected with Mała Bystrzyca river), flows through Garwolin and joins Vistula in WILGA Village. Wilga river is wild with numerable bends. After 1980 gains again clear water. The name of WILGA river (the word wilga in Polish) has the same core as moisture. WILGA river flows closely to WILGA Village resort owned by Warsaw Univ. Technology. Now, the clear waters of WILGA river invite one for swimming.

WILGA - a rural community in Mazowia Voivodeship, in Garwolin county. WILGA community has 5500 inhabitants, area $120 \mathrm{~km}^{2}$, above $40 \%$ forests and around $40 \%$ fertile fields. During WILGA Symposium the number of WILGA Community inhabitants increased by 250-350 people.

WILGA - a village (site of WILGA Community) of historical names (since 1400): Wilka, Vilka, de Wilcza, Vylka. Name originates from WILGA river. A parish founded in 1407. During 1534-1650 WILGA possesed town rights. Between the WWI and WWII the natural resort values of WILGA were discovered. Since this time the WILGA Resort Village has been developed in the adjacent woods. In 1944 fights of warecko-magnuszewski foothold. Localization of WILGA Resort Village is shown on the map quoted from Google Earth. The resort has now a few thousand homes. Among them is a resort owned by WUT. It is situated a few hundred $m$ from Vistula embankment. The road from $\mathrm{N}$ to $\mathrm{S}$ goes from Warsaw, via Dęblin to Puławy and Kazimierz upon Vistula. A branch road to E goes to Garwolin and a road Warszawa-Lublin. The left lower corner of the map shows the great, wild Vistula river. 


\section{CONCLUSIONS AND REASONS OF WILGA SYMPOSIUM SUCCESS}

Speaking the truth, it is not quite understandable why WILGA gained such a big success among young researchers, in a relatively dense market of conferences. This success is really outstanding, taking into account the number of participating each year Ph.D. students and a relatively narrow topical scope of the WILGA meeting. Perhaps these reasons are: no conference fee at all; no typical conference formalities; meeting is organized by students for young researchers; the symposium is not a part of any "grown up" and thus more important event; the papers are presented only in English; papers are peer-reviewed - by the students' tutors, during the presentation by the listeners and before publication by external reviewers; all accepted papers are published internationally, either in IEEE or SPIE press; publications give a considerable number of categorization points to the authors.

The lack of any formalities and low costs enable young scientists for easy arrival, participation and direct presentation of own papers in WILGA. WILGA accepts only original work by young scientists. Review work may be only presented by tutors as an introduction to topical sessions filled with students' work. WILGA lasts the whole week, which gives a lot of flexibility to the active participants in planning a proper term for their topical sessions. Weakly formalized character of special research, late night sessions at a grill encourages young scientists to utter their real opinions of own worked out research methods, local work conditions and perspectives of research career in this country and abroad. A generous sponsor for these late night session is Poland Section of IEEE.

Professor Ryszard S. Romaniuk (R.Romaniuk@spie.pl) Warsaw University of Technology, Faculty of Electronics and Information Technology SPIE Poland Chapter, IEEE Poland Section, WILGA Symposium Chair 


\title{
JACHRANKA CONFERENCE
}

It is the third time when DSP and Radar Imaging Conference, known also as Signal Processing Symposium SPS-2007, was organized in the frame of SPIE-IEEE WILGA SYMPOSIUM. The participants presented number of very high quality papers on very "hot" subjects such as high resolution radar imaging, image processing, feature extraction, signal processing, optical technology and radio-frequency technology. The conference was addressed to young scientist, PhD candidates and students. The experienced scientists ware also invited to present the tutorial papers showing new achievements and trends in science and technology.

In 2003, 12th IEEE-SPIE Symposium was organized and for the first time within the frame of this symposium the Digital Signal Processing and Radar Signal Processing Conference (SPS-2003) took place. This conference was organized by Institute of Electronic Systems, Warsaw University of Technology. Almost the whole conference was organized by students from the Radiolocation and Digital Signal Processing Students' Research Group. In May 2004 for the first time the big international radar conference - International Radar Symposium IRS-2004 was organized in Poland. In 2005 for the second time the DSP and Radar Imaging Conference (SPS-2005) was organized as a part of the 16th IEEE-SPIE Symposium on Photonics, Electronics and Web Engineering. SPS-2005 gathered more than 100 participants from 4 countries. More than sixty high level papers were presented at oral and poster sessions. It has been assessed as a very successful event. In 2005 the Polish and German radar society decided that each second (even) year the International Radar Symposium would be organized in May in Poland in the frame of the Microwave and Radar Weeks in Poland. To avoid two radar conferences in Poland in May, it was decided that DSP and Radar Imaging Conference (Signal Processing Symposia) would also be organized in each second year (odd). So the third DSP and Radar Imaging Conference (SPS2007) was organized on 24th-26th May 2007. Due to the increasing number of participants of SPIE-IEEE WILGA SYMPOSIUM it was not possible to share this some holiday camp in Wilga village so SPS-2007 had been shifted to Jachranka village - very nice holiday place placed at the bank of the artificial lake "Zalew Zegrzyński", $30 \mathrm{~km}$ East-North from Warsaw. The conference gathered more than 70 participants from 8 countries.
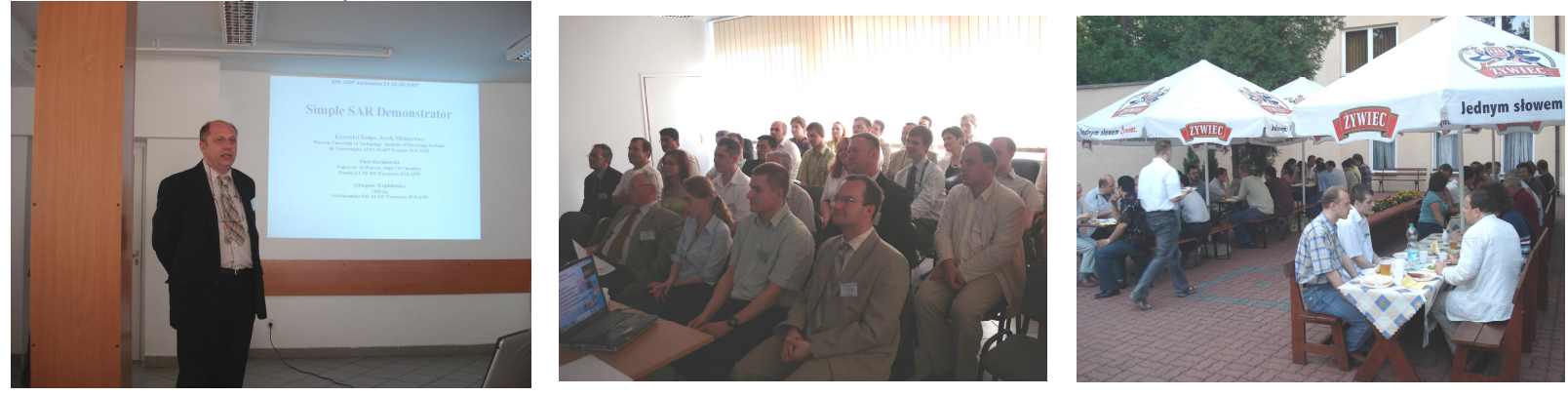

The SPS-2007 was sponsored by Telecommunication Research Institute (Warsaw, Poland), RADWAR S.A. (Warsaw, Poland) and Foundation for development of Radio-communication and Multi-media Technology (Warsaw, Poland). Thanks to their Sponsorship there was no conference fee and about $30 \%$ of participants could attend conference without any costs.

\author{
Dr. Krzysztof S. Kulpa (KKulpa@ieee.org) \\ Warsaw University of Technology, Faculty of Electronics and Information Technology \\ SPS-2007 Conference Chair
}




\title{
Palindromes in mathematics \\ Wojciech Plandowski \\ Department of Mathematics \\ Warsaw University, Poland
}

\begin{abstract}
The paper concerns palindromes in mathematics. Palindromes are structures which are the same when read forward and backward. There are debated basic properties of these data work structures in mathematics.
\end{abstract}

Keywords: Palindromes

\section{INTRODUCTION}

Everyone knows what a palindrome is. It is a text which is the same when reading forward and backward. One of the examples is the palindrome: " $\mathrm{C}$ is a basic". This palindrome can be extended to a palindrome of unbounded length: " $\mathrm{C}$ is a basic, is a basic, is a basic, ...".

Palindromes in mathematics have a little bit more precise definition. Namely, each letter including space is important. Lower-case and capital letters are considered as different letters. Using this definition " $\mathrm{C}$ is a basic" is not a palindrome because after the capital $\mathrm{C}$ is space while before the last $\mathrm{c}$ is not a space. Moreover, the first $\mathrm{C}$ is a capital letter while the last $\mathrm{c}$ is a lower-case letter. A palindrome in a mathematical sense is "cisabasic".

Palindromes in mathematical sense do not have to have a meaning, for instance the sequence of letters "abbabba" is a good palindrome. Palindromes are considered mainly in two branches of mathematics: combinatorics on words and text algorithms. They are occur also in number theory and formal language theory. In combinatorics on words palindromes occur in several theorems dealing with Sturmian words. In text algorithms there are several algorithms which checks properties of the input text - properties connected to palindromes. In number theory numbers which looks like palindromes are studied. In formal language theory the set of palindromes is an example of a language which is contextfree and which is not deterministic context-free. We will study one example of occurrence of palindromes in combinatorics o words and one in text algorithms .

\section{PALINDROMES IN COMBINATORICS ON WORDS}

Combinatorics on words studies properties of words including their structure and regularities which occur inside them. Palindrome is some kind of regularity. Palindromes in combinatorics on words occur in several theorems [2]. We will explain they relation to one of the most basic and important theorems in this branch of mathematics - Fine and Wilf's Theorem. To explain this theorem we have to introduce a few definitions.

A letter is either ' $a$ ' or ' $b$ '. $A$ word is any sequence of letters, for instance "abbabbabbabba". The number of letters in a word $\mathrm{w}$ is called the length of $\mathrm{w}$ and is denoted by $|\mathrm{w}|$. The $\mathrm{i}$-th letter of a word $\mathrm{w}$ is denoted by $\mathrm{w}[\mathrm{i}]$. We have $\mathrm{w}=\mathrm{w}[1] \mathrm{w}[2] \ldots \mathrm{w}[|\mathrm{w}|]$. A period of a word $\mathrm{w}$ is a number $\mathrm{p}$ such that $\mathrm{w}[\mathrm{i}]=\mathrm{w}[\mathrm{i}+\mathrm{p}]$, for $1 \leq \mathrm{i} \leq|\mathrm{w}|-\mathrm{p}$. If $\mathrm{p}$ is a period of $\mathrm{w}$, then $\mathrm{w}$ is of the form uuu..uu' where $\mathrm{u}=\mathrm{w}[1] \ldots \mathrm{w}[\mathrm{p}]$ and $\mathrm{u}^{\prime}=\mathrm{w}[1] \ldots \mathrm{w}[\mathrm{k}]$, for some $\mathrm{k} \leq \mathrm{p}$. It is not difficult to see that if $\mathrm{p}$ is a period of $w$, then $2 p, 3 p$ and all other multiples of $p$ are periods of $w$.

Example. We have abababa[2]=b. The length of abababa is 7 . Numbers 2, 4, 6, 7 are periods of abababa. Since 4 is a period of abababa the word abababa is in form uu' where $\mathrm{u}=\mathrm{abab}$ and $\mathrm{u}$ '=aba.

Denote by $\operatorname{gcd}(\mathrm{p}, \mathrm{q})$ the greatest number which divides both $\mathrm{p}$ and $\mathrm{q}$. For instance, $\operatorname{gcd}(15,25)=5$. Then the Fine and Wilf Theorem can be formulated in the following way.

Fine and Wilf's Theorem. Let $p$ and $q$ are two periods of a word $w$. If $p+q-\operatorname{gcd}(p, q) \leq|w|$, then $\operatorname{gcd}(p, q)$ is also a period of w.

Observe here that if $\operatorname{gcd}(\mathrm{p}, \mathrm{q})$ is period of $\mathrm{w}$, then $\mathrm{p}$ and $\mathrm{q}$, as multiples of $\operatorname{gcd}(\mathrm{p}, \mathrm{q})$, are also periods of w. For $\operatorname{gcd}(\mathrm{p}, \mathrm{q})=1$, the Fine and Wilf Theorem can be formulated in the following way. 
Fine and Wilf's Theorem $(\operatorname{case} \operatorname{gcd}(\mathbf{p}, \mathbf{q})=\mathbf{1})$. Let $\mathrm{p}$ and $\mathrm{q}$ are two periods of a word $w$. Let $\operatorname{gcd}(\mathrm{p}, \mathrm{q})=1$. If $\mathrm{p}+\mathrm{q}-1 \leq|w|$, then $w$ consists only of letters a or only of letters $b$.

An interesting question is: what happens if $\mathrm{p}$ and $\mathrm{q}$ are periods of $\mathrm{w}, \operatorname{gcd}(\mathrm{p}, \mathrm{q})=1$ and $|\mathrm{w}|=\mathrm{p}+\mathrm{q}-2$ ? Does $\mathrm{w}$ has to consists only of letters a or only of letters $b$ ? The answer is: No. For each $p, q$ such that $\operatorname{gcd}(p, q)=1$ there is a word $w$ of length $p+q-2$ which contains letters $a$ and $b$ and such that $p$ and $q$ are periods of $w$. This means that there is a sense of introducing the following definition. A word $\mathrm{w}$ is central if there are numbers $\mathrm{p}$ and $\mathrm{q}$ such that $|\mathrm{w}|=\mathrm{p}+\mathrm{q}-2$ and $\mathrm{p}$ and $\mathrm{q}$ are periods of w. Such words are characterized by the following theorem.

Theorem A word $w$ is central if and only if either consists only of letters a, or only of letters $b$, or $w$ is a palindrome and $\mathrm{w}$ is of the form uabv where $\mathrm{u}$ and $\mathrm{v}$ are palindromes.

\section{PALINDROMES IN TEXT ALGORITHMS}

Text algorithms are a part of algorithmics which works on words called here texts. Palindromes in text algorithms has been studied in contexts of sequential algorithms [2] and of parallel algorithms [1]. We will study one algorithmic problem which leads to a very useful data structure for sequential algorithms connected to palindromes. We start by introducing a useful notation. By $w[i . . j]$ we mean the word $w[i] w[i+1] \ldots w[j]$. The problem we are interested in is a basic one.

Problem: Given a word w. Design a data structure which allows, for a given two positions $\mathrm{i}$ and $\mathrm{j}$ of the word w, check whether $w[i . . j]$ is a palindrome.

An obvious solution of our problem is to build a two-dimensional boolean array $p[i, j]$, for $1 \leq i \leq j \leq|w|$ such that $p[i, j]=$ true if and only if $w[i . . j]$ is a palindrome. Using the array $p$ we can answer the question whether $w[i . . j]$ is a palindrome in constant time. However, this solution has one drawback: the size of a data structure $p$ is quadratic with respect to the length of w so any algorithm which computes this data structure has to work in at least quadratic time.

A solution proposed by Manacher is more tricky. From this moment we assume that we are interested only in even palindromes, that is $\mathrm{j}-\mathrm{i}+1$ in our problem is even. Extension to all palindromes is not difficult task and is left to the reader. We compute an array of integers $R$ such that $R[i]$ is the maximal number $j$ such that $w[i-j . . i+j-1]$ is a palindrome. Clearly, the size of the array is linear with respect to $|\mathrm{w}|$.

$\mathrm{R}[\mathrm{i}]$ is just a radius of a maximal even palindrome which is centered between positions $\mathrm{i}-1$ and $\mathrm{i}$ in $\mathrm{w}$. If we want to check whether $w[i . . j]$ is an even palindrome we just check whether $R[(j+i+1) / 2] \geq(j-i+1) / 2$, that is whether the radius of the maximal palindrome centered in the center of $w[i . . j]$ is greater than half of the length of $w[i . . j]$.

Example. Take a word abbaa. Then R[3] $=2$ since the largest even palindrome centered between positions 2 and 3 is abba and $R[5]=1$ since the largest even palindrome centered between positions 4 and 5 is aa.

The computation of $\mathrm{R}$ in quadratic time is a very simple task. We leave it to the reader. Linear time algorithm is not simple and it requires some reasoning from combinatorics on words. The reader which is interested in it is encouraged to read [2].

Theorem The array R can be computed in linear time.

\section{REFERENCES}

1. A. Apostolico, D. Breslauer, Z. Galil, "Parallel detection of all palindromes in a string".

2. L. Banachowski, A. Kreczmar, W. Rytter, Sprawdzanie własności syntaktycznych tekstów związanych z palindromami”, Chapter 3.3 in "Analiza Algorytmów i Struktur Danych", WNT 1989 (in Polish), p. 176-188.

3. M. Lothaire, "Sturmian words", Chapter 2 in "Algebraic Combinatorics on Words", Cambridge University Press 2002, p. $45-110$. 